\title{
An Integrated Statistical-Graphical Approach for the Appraisal of the Natural Background Levels of Major Ions and Some Potentially Toxic Elements in the Groundwater of Urmia Aquifer, Iran
}

Vahab Amiri ( $\nabla$ vahab.amiri@gmail.com )

Yazd University https://orcid.org/0000-0001-9734-9812

Mohammad Nakhaei

Kharazmi University

Razyeh Lak

Geological Survey of Iran: Geological Survey and Mineral Exploration of Iran

Peiyue Li

Chang'an University

\section{Research Article}

Keywords: Natural Background Level, Groundwater Pollution, Human Effects, Iterative $2 \sigma$ Technique, Calculated Distribution Function, Ambient Background Level

Posted Date: March 22nd, 2021

DOl: https://doi.org/10.21203/rs.3.rs-329738/v1

License: (c) (i) This work is licensed under a Creative Commons Attribution 4.0 International License.

Read Full License 
12 2. Department of Applied Geology, Faculty of Earth Science, Kharazmi University, Tehran, Iran.

13 E-mail: $\underline{\text { nakhaei@khu.ac.ir }}$

14 3. Research Institute for Earth Sciences, Geological Survey of Iran, Tehran, Iran. E-mail:

15 lak_ir@yahoo.com

16 4. School of Water and Environment, Chang'an University, No. 126 Yanta Road, Xi'an 710054,

17 China. E-mail: lipy2@163.com; peiyueli@chd.edu.cn

18 5. Key Laboratory of Subsurface Hydrology and Ecological Effect in Arid Region of the

19 Ministry of Education, Chang'an University, No. 126 Yanta Road, Xi'an 710054, China

20

$21 *$ Corresponding author 


\section{Abstract}

In this study, we attempted to calculate the Natural Background Level (NBL) for 19 selected chemical compounds in the Urmia aquifer, northwestern Iran. In this study, combined methods including pre-selection and statistical methods for determining NBL have been used. In the preselection method, the concentration of nitrate $\left(\mathrm{NO}_{3} \geq 19.97 \mathrm{ppm}\right)$ and chloride $(\mathrm{Cl} \geq 200 \mathrm{ppm})$ were used as the main criteria to identify and eliminate samples affected by human activities.

34 The selected concentration of nitrate is determined using the comparison of the results of various statistical and graphical evaluations including Quantile-Quantile plot (Q-Q plot), Box \& Whisker plot (BW), Box \& Whisker plot Iterative (BWI), Grubbs test, Mean and standard deviation $($ mean $\pm 2 \sigma)(M S D)$, and median absolute deviation (MAD). After identifying the final data set, the NBL of the selected chemical compounds was calculated by two techniques including the Iterative $2 \sigma$ technique $(2 \sigma)$ and calculated distribution function (CDF). Due to higher concentration relative to the reference values (REF), this study has focused on the calculation of NBL of $\mathrm{SO}_{4}, \mathrm{~F}, \mathrm{As}, \mathrm{Fe}$ and Mn. Results showed that the upper limit of NBL calculated for these variables is about 125 ppm, 1 ppm, $8.5 \mathrm{ppb}, 570 \mathrm{ppb}, 80 \mathrm{ppb}$, respectively. Given that no study has been conducted to determine the NBL of chemical compounds in groundwater in Iran, the results of this study can be a roadmap for decision-makers and researchers to better manage this aquifer and other water resources in this country with limited freshwater resources.

46 Keywords: Natural Background Level, Groundwater Pollution, Human Effects, Iterative $2 \sigma$

47 Technique, Calculated Distribution Function, Ambient Background Level

\section{Introduction}

49 Groundwater is one of the most important sources of water needs for various uses, especially

50 drinking so that about one-third of freshwater is extracted annually from groundwater sources

51 (Wang et al. 2018; Gao et al. 2020; Wang et al. 2020). In recent decades, the development of 52 cities and the increase of industrial activities have caused serious groundwater pollution, in 53 addition to overexploitation of groundwater resources ( $\mathrm{Li}$ et al. 2016, 2017; Wu et al. 2017).

54 Various pollutants enter the water and soil environment, which is threatening human health and 55 ecological security (Falkenmark, 2005; Amiri et al., 2020b; Sohrabi et al. 2020; Li et al. 2021). 56 Today, access to adequate and safe water has become one of the concerns of various 
governments. Therefore, quantitative and qualitative management of groundwater resources is 58 one of the most important and necessary measures to be taken to ensure the health of the consumer community (Sohrabi et al. 2013; Amiri et al. 2021b; Amiri and Berndtsson 2020).

In such circumstances, accurate assessment of the natural background level (NBL) of various chemical compounds and the determination of anthropogenic anomalies and effects are essential for the optimal management of groundwater quality (Gao et al. 2019, 2020). Determination of natural/geochemical background values was first proposed by Hawkes and Webb (1962) as the natural concentration of chemical elements and compounds in geological materials without the effect of anthropogenic agents. In 1993, the term geochemical baseline was introduced and many researchers considered it synonymous with NBL and used it to study natural changes in the concentration of chemical compounds in soil and water environments (e.g. Hernandez-Garcia and Custodio 2004; Bech et al. 2005).

In groundwater science, the natural background (baseline) level is the range of natural change of an element, species, or chemical compound in an aqueous solution of biological, geogenic, or atmospheric origin (Edmunds et al. 2003). However, some researchers believe that NBLs no longer exist today due to increased human activity; in other words, most water resources have varying degrees of anthropogenic effects (Li et al. 2014; Nakic et al. 2007; Sellerino et al. 2019; Gao et al. 2020). On the other hand, the calculated NBL for each chemical compound is determined by a threshold value (TV) (European Community 2006). Using these values, the quality of groundwater can be assessed more accurately.

Determining the role of natural and anthropogenic factors in controlling the chemical composition of surface/groundwater resources and different sediments and soils has been pursued by various researchers (Ren et al. 2021). Naturally, different methods are used for each of these studies, and each of them has advantages and disadvantages. Therefore, by analyzing these studies, the optimal method can be identified and used for the study area. Rotiroti et al. (2015) used a new component separation-based (CS) tool called COMPSEC to calculate background concentrations of heavy elements in different hydrogeological environments. The results showed that the CS method can be a suitable and reliable method for estimating the background value, but in some cases, the superimposition of a log-normal distribution for the natural component may not be sufficient. Kim et al. (2015) used a heuristic procedure to statistically determine the natural background and anthropogenic polluted levels of nitrate in 
groundwater. They showed that compared to classical methods, this method can use a finite

89 normal-mixture model to distinguish polluted samples from samples with natural concentrations

90 more accurately. Yan et al. (2019) evaluated the pollution and determined the background value

91 of heavy elements in the sediments using the methods of enrichment factor, geoaccumulation

92 index, contamination factor, principal component analysis, and cluster analysis. Sun (2019)

93 compared statistical and spatial analysis methods to determine background concentrations of lead

94 in groundwater. This study, using box plots and spatial autocorrelation analyzes, showed that the

95 appropriate method for determining background values should be selected based on the

96 distribution of elements or contaminants in aquatic environments. Duan et al. (2019) used a

97 three-step method including single index recognition, limiting factors, and a synthetic index to

98 distinguish the background values of some chemical parameters in surface waters.

99 In many studies, the NBL assigned to each chemical component is presented as a unique

100 value, which is incorrect given the nature of the change in groundwater chemical composition

101 (Nakic et al. 2007; Gao et al. 2020; Su et al. 2020; Ji et al. 2020). As mentioned before, change

102 in the chemical composition of groundwater triggers from the place and time of recharging and

103 after reacting with solid materials in the path of movement, it can be elevated by processes such

104 as surface water infiltration, biological activities, evapotranspiration, water abstraction, deep

105 saline water intrusion, agricultural return water infiltration and effluent of residential areas or

106 industrial units (Nakhaei et al. 2015; Ren et al. 2021; Sohrabi et al. 2017; De Caro et al., 2017;

107 Vázquez-Suñé et al., 2004; Amiri et al. 2021 a, b). Therefore, since the chemical composition of

108 groundwater is controlled by natural and anthropogenic factors, and the effect of these factors

109 changes in different places and times, the NBL should normally be considered as a range and not

110 a unique value (Nakic et al., 2007).

111 Statistical methods such as parametric and non-parametric approaches can determine the

112 NBL for the desired chemical compounds (De Caro et al. 2017). The role of natural and human

113 factors in controlling changes in chemical compounds in groundwater can be identified by

114 distribution functions and their normality (Wendland et al. 2005; Molinari et al. 2012). Unlike

115 nonparametric methods, most parametric methods can determine the NBL by assuming that the

116 data distribution follows a normal or log-normal distribution (such as $4 \sigma$ outlier test, $2 \sigma$ or

117 calculated distribution function $(\mathrm{CDF})$ ). These methods are based on determining and removing

118 anomalies from data sets and creating a normal distribution (Gałuszka, 2006; Nakic et al., 2007). 
119 Matschullat et al. (2000) by examining various methods such as $4 \sigma$-outlier, $2 \sigma$, and CDF 120 revealed that in the first method, a small number of samples are removed from the data set, in 121 other words, the computational NBL is estimated to be higher than the actual value. Therefore, if 122 the number of available data for each chemical compound is more than 30, two other methods 123 (i.e. $2 \sigma$ and CDF) can provide more accurate results (Gao et al. 2020).

124 So far, various studies have examined the background values of various elements and 125 compounds in soil and water environments. As a highly practical method, Nakic et al. (2007) 126 showed that removing outliers from the data set of some compounds in an iterative process can 127 lead to their normal distribution and NBL determination. Kelly and Panno (2008), Rodrigues et 128 al. (2013), Urresti-Estala et al. (2013), Preziosi et al. (2014), Salomão et al. (2018), Salomão et 129 al. (2019), Bulut et al. (2020), Gao et al. (2020) and Duan et al. (2020) used Iterative 2 $\sigma$ and 130 CDF methods to determine the NBL.

131 This study aimed to identify the factors that control the natural changes in the chemical 132 composition of groundwater resources as well as the possible role of anthropogenic factors. 133 Therefore, we have tried to use the Iterative $2 \sigma$ and CDF methods to calculate the NBL of the 134 main ions and some metallic and non-metallic elements in the coastal part of the Urmia aquifer, 135 northwestern Iran. So far, various hydrochemical, geochemical, isotopic, hydrogeological, and 136 geophysical studies have been performed by the authors in this aquifer (Amiri et al. 2016a, b, c, $1372017,2020,2021)$. In most of these studies, several possible sources have been proposed for 138 occasionally high concentrations of major and potentially toxic elements. Therefore, NBL 139 determination of such elements can be very effective in improving the management of

140 groundwater resources and preventing adverse consequences for the health of residents through 141 water consumption. This study is the first attempt to determine the NBL of elements in 142 groundwater in Iran and can be considered by many researchers in this country.

\section{Materials and Methods}

\section{Geology, climate, and hydrogeology of the study area}

145 Since the hydrogeological conditions and groundwater flow system can change the groundwater 146 chemistry, this section introduces the study area in terms of geology and hydrogeology. Urmia 147 aquifer (UA) with an area of nearly $750 \mathrm{~km}^{2}$ is located in northwestern Iran and west of Lake 148 Urmia as one of the salt lakes in the world with a salinity changing about 300-350 gr/L (Amiri 
and Berndtsson 2020). This aquifer is mostly unconfined, but in some areas, it has a convertible

150 structure. It is surrounded by various rock formations. The oldest rocks in this area belong to the

151 Precambrian. This area includes a collection of metamorphic rocks such as gneiss, amphibole,

152 metadiorite, volcanic structures, and carbonate rocks (Sohrabi et al. 2017 and 2018).

153 According to the global bioclimatic classification system, this area is located in the east of 154 the Zagros Mountains and the east of the Mediterranean climate range (Amiri et al. 2016a). 155 Moisture originating from the Mediterranean Sea is transferred to the region by cyclonic 156 currents. The average annual temperature in this region over the last 35 years is about $12{ }^{\circ} \mathrm{C}$. 157 Also, the average maximum and minimum temperature in the same time is about 31 and $-6{ }^{\circ} \mathrm{C}$, 158 respectively. Compared to the average rainfall of Iran (about $280 \mathrm{~mm}$ ), the average annual 159 rainfall in this area in the long period is about $346 \mathrm{~mm}$. The wet season in Urmia begins in late 160 October and early November and ends in June. The maximum rainfall is in March and April 161 (Amiri et al. 2021c).

162 Rainfall is the most important recharging factor of this aquifer. Besides, currents from 163 perennial rivers (including Nazluchai, Baranduz Chai, Shahr Chai, and Rouzeh Chai) and some 164 temporary rivers are other factors that recharge the aquifer. The connection of karst water 165 resources as well as hard rock formations through dissolution systems and fractures is also one of 166 the most probable factors in recharging groundwater resources (Amiri et al. 2016c). This aquifer 167 is drained by several thousand wells. Despite the high rate of rainfall in the aquifer, the 168 uncontrolled abstraction of groundwater due to the activity of more than 25,000 unlicensed wells 169 and 17,000 authorized wells has caused that in 34 years, the average drop in water level is equal to $15 \mathrm{~cm}$ annually and in 34 years is equal to $536 \mathrm{~cm}$ (IWRM 2017).

171 Geophysical studies show that the maximum thickness of the alluvial part of UA in its 172 northern half is about 160 meters, which is observed in the central and eastern regions (near 173 Urmia Lake (UL)). Also, its southern half has a maximum thickness of about 120 to 130 meters 174 and these changes are observed along the shore of UL and often in the central regions (Amiri et 175 al. 2016b).

176 This lake deepens from south to north. Therefore, it is expected that UA and UL have a 177 common bedrock. Due to the reduction of topographic slope from west to east, it is expected that 178 the groundwater level in this aquifer in the western regions is at a greater depth than the eastern 179 regions. Accordingly, by recharging the aquifer and reducing groundwater abstraction, in many 
180 coastal areas, the groundwater level is at a very shallow depth and close to the ground, even 181 when the water level of UL is lower than the groundwater level. Based on hydrogeochemical, 182 isotopic, and geophysical studies performed in this part of UA, there is little evidence of the

183 direct hydraulic relationship between fresh groundwater and UL, and this is due to the presence 184 of thick, very hard and impermeable salt layers at the border of these two water bodies (Amiri et 185 al. 2017).

\section{Data collection \& analysis}

187 In this study, 175 groundwater samples were collected from the eastern part of the Urmia 188 Aquifer. These samples were collected with the financial support of the Geological Survey and 189 Mineral Exploration of Iran in 2014 and 2015 and by the first author of this article. The initial 190 monitoring network consisted of 84 sampling locations and 91 duplicate samples were collected 191 from the network twice (Fig. 1). The depth of selected wells was between 10 and 120 meters 192 (with an average of 47 meters). All sampling, storage, laboratory transfer, and physicochemical 193 analysis processes are performed according to international standards (APHA 1985; ISO 1993).

194 At each sampling position, the collected water was stored in two $250 \mathrm{ml}$ PET bottles. To 195 extract freshwater without high retention time in the well, sampling was done from the pumping 196 wells and if the pump was off, the pumping was done for several minutes and then the water 197 sample was stored in a bottle. Before storing water, the bottles were washed several times with 198 the desired water. One bottle was used for the analysis of anions without any manipulation and 199 the other bottle, whose acidity was reduced by $65 \% \mathrm{v} / \mathrm{v}$ nitric acid $(\mathrm{pH} \approx 2)$, was used to analyze 200 cations and other elements. Before analysis, these samples were stored at standard temperature (4 $\left.201{ }^{\circ} \mathrm{C}\right)$. Some physical parameters including electrical conductivity (EC), total dissolved solids 202 (TDS), $\mathrm{pH}, \mathrm{Eh}$, and temperature were measured on-site using a HACH Multimeter device. 203 Besides, the concentrations of chemical parameters include $\mathrm{SO}_{4}, \mathrm{~F}, \mathrm{Cl}, \mathrm{NO}_{3}, \mathrm{HCO}_{3}+\mathrm{CO}_{3}, \mathrm{Ca}, \mathrm{K}$, $204 \mathrm{Mg}, \mathrm{Na}, \mathrm{B}, \mathrm{Br}, \mathrm{Al}, \mathrm{As}, \mathrm{Ba}, \mathrm{Cd}, \mathrm{Fe}, \mathrm{Li}, \mathrm{Mn}, \mathrm{Mo} \mathrm{Ni}, \mathrm{P}, \mathrm{Rb}, \mathrm{Se}, \mathrm{Si}, \mathrm{Sr}, \mathrm{U}$, and Zn were also 205 measured in the laboratory. 

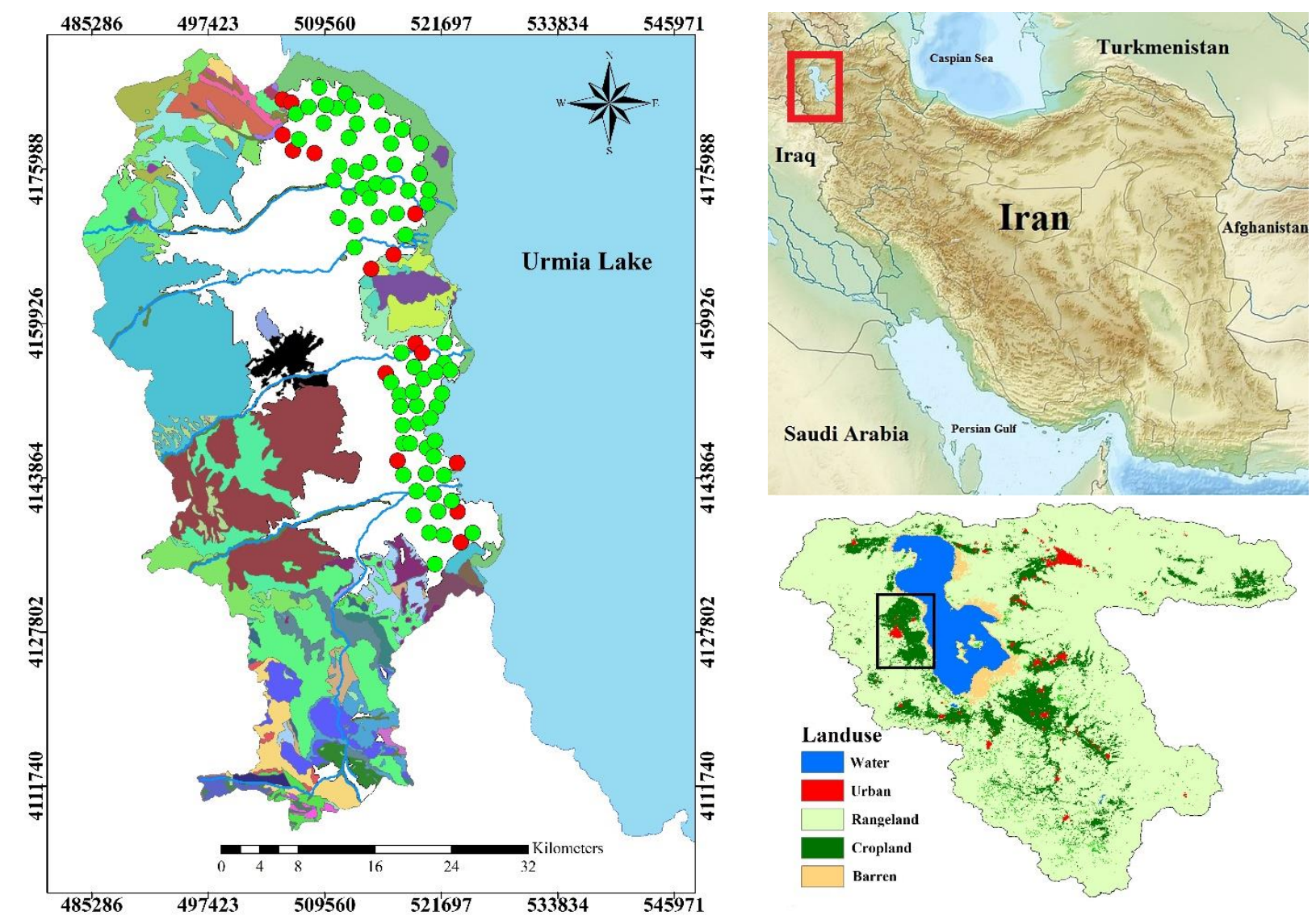
Legend
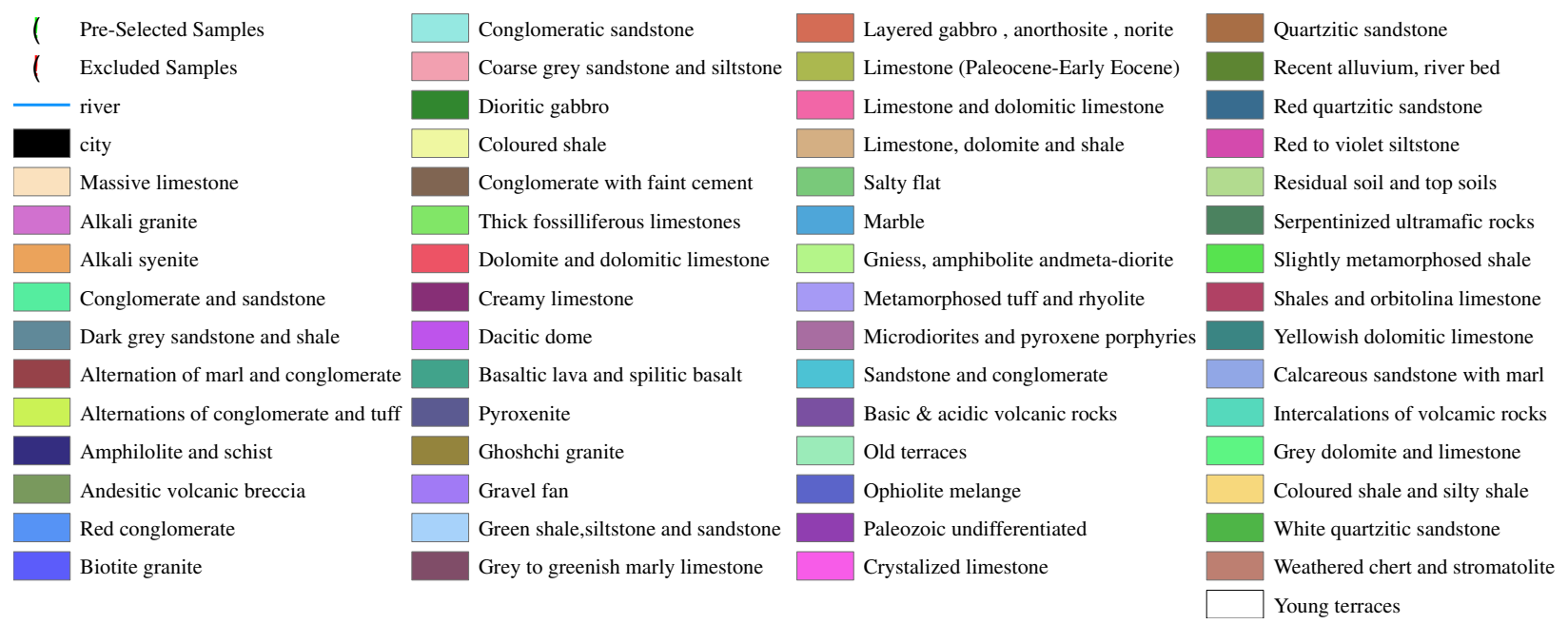

Fig. 1 Geographical location of the study area. Green circles: included water samples, red circles: excluded water samples

208 Based on geological, hydrogeological, hydrogeochemical studies and the authors' experience 209 in the study area, we have tried to calculate the NBLs of 19 chemical compounds in the 210 groundwater. According to studies, the selected compounds have both natural (geochemical) and 211 human (due to agricultural, industrial, and mining activities). 
213 In this study, Iterative $2 \sigma$ and CFD methods were used to determine the NBL of various 214 chemical compounds in groundwater.

215 In the Iterative $2 \sigma$ method, after calculating the mean and standard deviation of the data set, 216 the mean $\pm 2 \sigma$ calculation is repeated until the data follow the normal distribution (Matschullat et 217 al. 2000). Thus, all outliers are removed from the mean $\pm 2 \sigma$ range and they are considered as 218 data affected by anthropogenic factors. The process of calculating and plotting the distribution of 219 data is repeated until all the data fall in the desired range (i.e. mean $\pm 2 \sigma$ ). The data in the 220 calculated range is known as the NBL and the upper limit of this range is considered as the 221 background value (Rodrigues et al., 2013). The Lilliefors test is used to check the frequency 222 distribution and normality of the data. Besides, the $t$-test is used to calculate the $t$-statistic and the 223 value obtained is compared with the $t$-critical value ( $t$-crit.). In these calculations, $\alpha$ and 224 confidence level are 0.05 and $95 \%$, respectively. If the $t$-statistic is lower than the $t$-crit., the data 225 distribution is normal and this method is suitable for determining the NBL of the desired 226 chemical compounds (Urresti-Estala et al., 2013). In this method, the upper mean $\pm 2 \sigma$ can be 227 considered as TV (Nakic et al. 2007).

228 The CDF method works on the basis that human factors can increase the concentration of chemical compounds in groundwater. Similar to the Iterative $2 \sigma$ technique, this method tries to

230 fit a normal curve on the data sets. In this method, samples with a concentration higher than the 231 median are excluded from the data set, and in contrast, it is assumed that the samples in which 232 the concentration of the studied parameter is between min. and median, are unaffected by 233 anthropogenic effects (Matschullat et al. 2000). In this way, the remaining values can be 234 considered as NBL (Urresti-Estala et al. 2013). In both the Iterative $2 \sigma$ and CDF method, 235 determining acceptable NBLs for different compounds is depends on the frequency distribution 236 of the data set as well as their nature (Bulut et al. 2020).

237 In this study, a Visual Basic macro entitled BACKGROUND, developed by Nakić et al. 238 (2007), has been used to calculate the NBLs based on Iterative $2 \sigma$ and CDF methods. One of the 239 essential information for calculating Iterative $2 \sigma$ and CDF is to determine the interval or bin 240 value for each of the desired physicochemical compounds. In this study, Strurge's Rule, which is 241 a function of the number of samples ( $n$ ) and the min. and max. of a chemical variable in the data 242 set, was used to calculate the bin value (Salomão et al. 2019; Eq.1): 
243 Bin value $=\frac{1+3.222 \times\left(\log _{10}^{\mathrm{n}}\right)}{\text { Max. }- \text { Min. }}$

244 In cases where the concentration of a chemical variable is less than the detection limit of the 245 measuring device, dividing the min. value by the square root of 2 has been used as an alternative 246 (Amiri et al. 2017; Succop et al. 2004).

\section{Results and Discussion}

249 One of the challenges in determining the NBL of various chemical compounds in groundwater is 250 how to identify and determine samples affected by anthropogenic factors (Biddau et al., 2017; 251 Cruz and Andrade, 2015). Nitrate is one of the most common human contaminants that can be 252 easily measured (Almasri 2007; Masetti et al. 2008; Mencio et al. 2016; Li et al. 2019). 253 Therefore, in several studies, it has been used as a criterion for identifying groundwater pollution 254 by human activities and for the pre-selection of data sets. In some studies, samples with a nitrate 255 content of more than $10 \mathrm{ppm}$ were considered contaminated and removed from the data set 256 (Muller et al. 2006). However, in areas with intensive agricultural activities, the concentration of 257 nitrate in groundwater increases more than usual, and therefore, considering the $10 \mathrm{ppm}$ limit for 258 the pre-selection process leads to the elimination of a large number of samples and unacceptable 259 reductions in the size of data set (Preziosi et al. 2010).

260 Given in the importance of the number of samples remaining in a data set, it is important to 261 select the appropriate concentration of nitrate as a criterion for the pre-selection step. As a first 262 suggestion, Muller et al. (2006) used $\mathrm{NO}_{3} \geq 10 \mathrm{mg} / \mathrm{L}$ for the pre-selection of the data set. Some 263 studies have suggested that $75 \%$ of the standard drinking water (WHO 2011) equal to $37.5 \mathrm{mg} / \mathrm{L}$ 264 can be used. Nevertheless, Parrone et al. (2019) showed that selecting a local value or limit 265 appropriate to the study area can help to better understand the chemical behavior of groundwater 266 resources and select a more optimal data set. Accordingly, this calculated value should not 267 exceed $37.5 \mathrm{mg} / \mathrm{L}$. This criterion of separation of affected and non-affected samples by nitrate 268 concentration has not been studied comprehensively. According to the definition of Reimann and 269 Garrett (2005), these limits are considered as Ambient Background Level (ABL).

270 In this study, the local ABL of nitrate was determined using the following methods: 
- Quantile-Quantile plot (Q-Q plot): The concentration of nitrate is displayed using this distribution method, and after identifying inflection points, values outside the main trends are recognized as outliers and removed from the data set.

- Box \& Whisker plot $(B W)$ : In this method, the distribution of nitrate in the study area is shown using the BW method, and outliers are removed from the original data set.

- Box \& Whisker Iterative (BWI): By repeating the remaining data from the BW method, any remaining outliers are identified and removed. This method continues until all outliers are removed from the data set.

- Mean and standard deviation (MSD): In this method, the mean value and standard deviation $(\sigma)$ of the data set are calculated and considering the mean $\pm 2 \sigma$, at each step a part of the samples with nitrate content outside this range is excluded. In this method, the calculations using the remaining data must be repeated until the desired result is obtained.

- Grubbs test: This parametric method is a suitable tool for identifying outliers using Z$\mathrm{G}_{\mathrm{t}}=\frac{\left(\mathrm{x}_{\mathrm{s}}-\mu\right)}{\sigma}$

Where $\mu$ is the mean of the data set, $\sigma$ is the standard deviation, $\mathrm{x}_{\mathrm{s}}$ is the suspected value, and $\mathrm{G}_{\mathrm{t}}$ is the Grubbs test.

- Mean absolute deviation (MAD): In this method, we have tried to calculate the MAD value of the data set and remove samples with values above the threshold of 4.5 from the data set (Parrone et al. 2019).

294 Fig. 2 shows the processes performed on nitrate data using the Q-Q plot, Box \& Whisker plot, 295 and Grubbs test methods. 


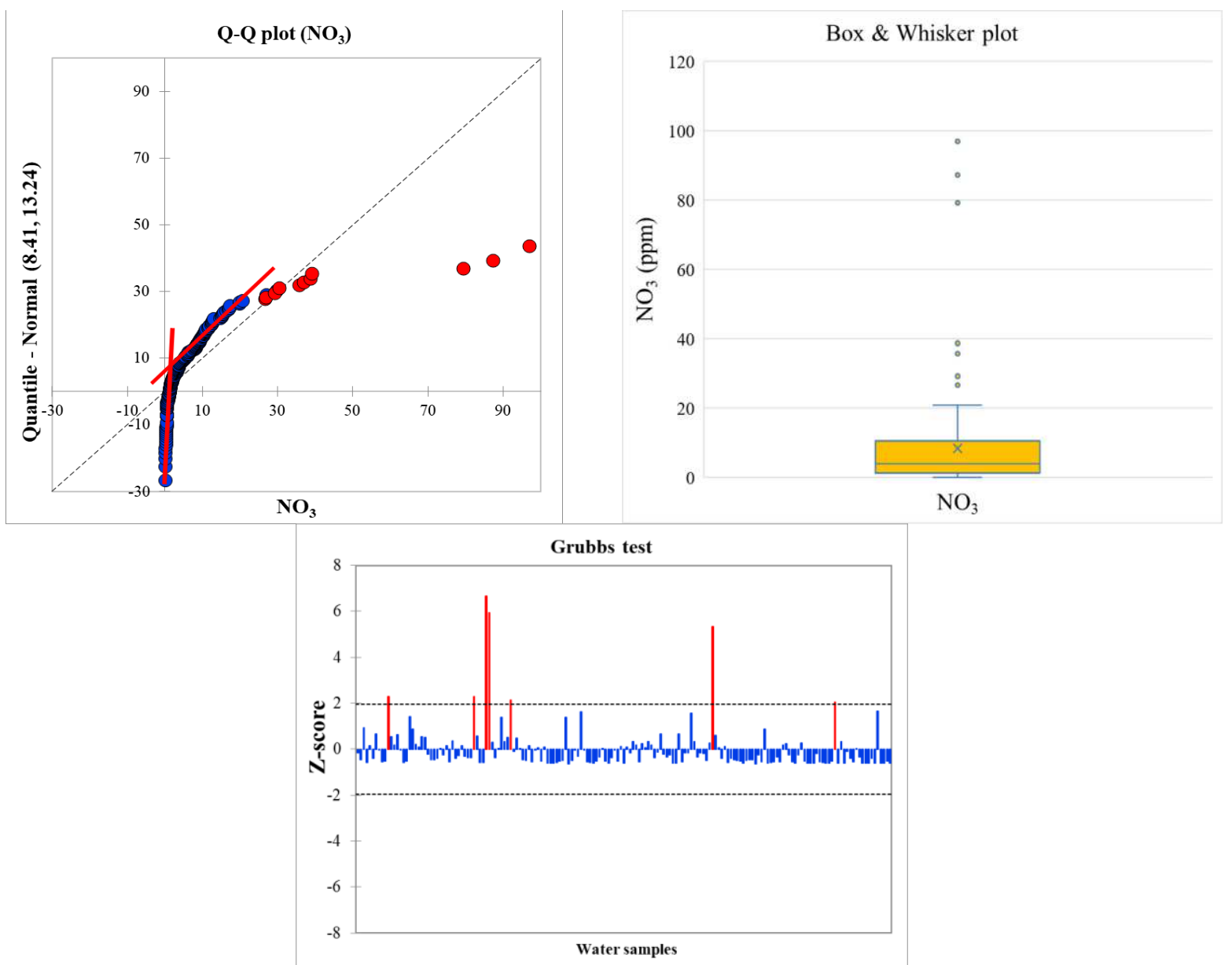

296 Fig. 2 Identifying the outliers in nitrate data set by Q-Q plot, BW, and Grubbs test.

Then, by comparing the results, examining the distribution curves, and their normality, the 299 final value obtained was determined by each method. In each method, if after statistical 300 calculations and a graphical representation, the distribution of the remaining data set after 301 removing the outliers was normal, the maximum value was considered as the final number. The 302 Shapiro-Wilk test was used to determine the normality of the remaining data sets (Shapiro and 303 Wilk 1965). Otherwise, the 95th percentile of the remaining data was considered as ABL of 304 nitrate. After determining the local ABL of nitrate, samples containing greater values were 305 considered as affected by human activities and removed from the original data set. In addition to 306 nitrate, a recommended amount of chloride $(\mathrm{Cl} \geq 200 \mathrm{ppm})$ was used to increase the accuracy of 307 selecting samples unaffected by human activities (Ducci et al. 2016). Finally, these pre-selected 308 data were used to calculate the NBL of the chemical compounds using Iterative $2 \sigma$ and CDF 309 methods. 
310 The results of ABL nitrate calculation using different methods are presented in Table 1. 311 Accordingly, the three methods, including Q-Q plot, BW, and BWI, offer the same values of $31216.23 \mathrm{ppm}$. The similarity of the values obtained by these methods has already been reported by 313 Parrone et al. (2019). On the other hand, the computational ABL by the Grubbs test method is 314 equal to $19.97 \mathrm{ppm}$. As expected, the MSD method provides less value. Due to the intensive 315 agricultural activities in the Urmia plain (see Fig. 1) and the average nitrate concentration in 316 these samples (about $8.5 \mathrm{ppm}$ ), it seems that a more conservative amount of nitrate should be 317 considered. On the other hand, considering low ABL values leads to deleting a large number of 318 samples and decreasing the data set. So we decided to consider $19.97 \mathrm{ppm}$ as the final ABL.

Table 1 Results of the pre-selection process

\begin{tabular}{|c|c|c|}
\hline & Q-Q plot ${ }^{\mathrm{a}}$ & 16.23 \\
\hline Methods for calculation of $\mathrm{ABL}$ of & $\mathrm{BW}^{\mathrm{b}}$ & 16.23 \\
\hline $\mathrm{NO}_{3}$ & $\mathrm{BWI}^{\mathrm{c}}$ & 16.23 \\
\hline (values are in ppm and equal to 95 & Grubbs test & 19.97 \\
\hline \multirow[t]{2}{*}{ percentile of remaining data sets) } & $\operatorname{MSD}^{\mathrm{d}}$ & 1.89 \\
\hline & $\mathrm{MAD}^{\mathrm{e}}$ & 12.63 \\
\hline \multirow[t]{2}{*}{ Final $\mathrm{ABL}$ of $\mathrm{NO}_{3}(\mathrm{ppm})$} & & 19.97 \\
\hline & Min. & 34 \\
\hline \multirow[t]{3}{*}{$\mathrm{Cl}(\mathrm{ppm})$} & Mean & 501.93 \\
\hline & Max. & 2061.4 \\
\hline & Min. & 0.5 \\
\hline \multirow[t]{3}{*}{$\mathrm{NO}_{3}(\mathrm{ppm})$} & Mean & 23.20 \\
\hline & Max. & 97 \\
\hline & $\begin{array}{l}\mathrm{Cl} \text { excess } \\
(\geq 200 \mathrm{ppm})\end{array}$ & 28 \\
\hline \multirow[t]{3}{*}{$\begin{array}{l}\text { Exclusion criteria } \\
\text { (\# of samples) }\end{array}$} & $\begin{array}{l}\mathrm{ABL} \text { of } \mathrm{NO}_{3} \\
(\geq 19.97 \mathrm{ppm})\end{array}$ & 15 \\
\hline & $\begin{array}{c}\text { Both } \\
\left(\mathrm{Cl} \geq 200 \mathrm{ppm}, \mathrm{NO}_{3} \geq 19.97 \mathrm{ppm}\right)\end{array}$ & 8 \\
\hline & All & 35 \\
\hline \multirow[t]{3}{*}{ Excluded samples } & Northern part & 19 \\
\hline & Southern part & 16 \\
\hline & All & 140 \\
\hline \multirow[t]{2}{*}{ Included samples } & Northern part & 68 \\
\hline & Southern part & 72 \\
\hline
\end{tabular}

${ }^{a}$ Quantile-Quantile plot, ${ }^{\mathrm{b}}$ Box \& Whisker plot, ${ }^{\mathrm{c}}$ Box \& Whisker plot Iterative, ${ }^{\mathrm{d}}$ Mean and standard deviation

322 (mean $\pm 2 \sigma),{ }^{\mathrm{e}}$ Median absolute deviation

323 In addition to nitrate, according to the hydrogeological conditions and the location of the 324 study area near the Urmia Salt Lake, another criterion $(\mathrm{Cl} \geq 200 \mathrm{ppm})$ was used for the pre325 selection step. Based on these two criteria, 35 samples affected by human activities were 326 removed from the data set. Thus, the number of samples was reduced from 175 to 140. 
327 Subsequently, NBL of different chemical compounds were determined using these 140 samples.

328 Table 2 provides statistical information related to the original and final data set selected by the 329 pre-selection process.

Table 2 Statistics of the original data and final selected data

\begin{tabular}{|c|c|c|c|c|c|c|c|c|c|c|c|c|}
\hline & \multicolumn{6}{|c|}{ Original Data } & \multicolumn{5}{|c|}{ After Pre-selection } & \multirow{3}{*}{ Max. } \\
\hline & \multirow{2}{*}{ Min. } & \multicolumn{4}{|c|}{ Percentile } & \multirow{2}{*}{ Max. } & \multirow{2}{*}{ Min. } & \multicolumn{4}{|c|}{ Percentile } & \\
\hline & & 25 th & 50th & 75 th & 95th & & & 25 th & 50th & 75th & 95th & \\
\hline $\mathrm{EC}(\mu \mathrm{S} / \mathrm{cm})$ & 289.0 & 616.0 & 918.0 & 1364.0 & 3448.0 & 7180.0 & 289.0 & 569.8 & 762.5 & 1079.0 & 1636.5 & 2200.0 \\
\hline TDS (ppm) & 144.5 & 300 & 482 & 690 & 2132 & 6462 & 144.5 & 282.5 & 383.8 & 578.0 & 991.3 & 1312.5 \\
\hline Temperature $\left({ }^{\circ} \mathrm{C}\right)$ & 13 & 16 & 17 & 18 & 20 & 23 & 13.0 & 16.0 & 17.0 & 18.0 & 20.0 & 22.0 \\
\hline $\mathrm{pH}$ & 6.05 & 7.18 & 7.37 & 7.62 & 7.94 & 8.92 & 6.8 & 7.2 & 7.4 & 7.7 & 7.9 & 8.9 \\
\hline $\mathrm{Eh}(\mathrm{mV})$ & -88 & -35.4 & -16.6 & 5.87 & 22.982 & 73.70 & -88.0 & -42.2 & -19.3 & 2.5 & 20.3 & 33.1 \\
\hline $\mathrm{SO}_{4}(\mathrm{ppm})$ & 0.5 & 39.0 & 74.0 & 155.0 & 452.0 & 980.0 & 0.5 & 32.3 & 63.0 & 124.3 & 319.0 & 500.0 \\
\hline $\mathrm{F}(\mathrm{ppm})$ & 0.1 & 0.4 & 0.6 & 1.2 & 2.8 & 5.7 & 0.1 & 0.4 & 0.5 & 0.9 & 2.1 & 5.7 \\
\hline $\mathrm{Cl}(\mathrm{ppm})$ & 6.1 & 18.5 & 38.0 & 122.5 & 659.6 & 2061.4 & 6.1 & 14.1 & 30.0 & 55.0 & 144.8 & 200.0 \\
\hline $\mathrm{NO}_{3}(\mathrm{ppm})$ & 0.1 & 1.2 & 3.9 & 10.5 & 29.9 & 97.0 & 0.1 & 1.0 & 3.0 & 9.1 & 15.5 & 17.3 \\
\hline $\mathrm{HCO}_{3}+\mathrm{CO}_{3}(\mathrm{ppm})$ & 78.5 & 171.9 & 323.2 & 509.8 & 833.2 & 1084.8 & 78.5 & 161.1 & 315.6 & 484.1 & 726.1 & 965.8 \\
\hline $\mathrm{Ca}(\mathrm{ppm})$ & 3.5 & 52.0 & 85.0 & 132.9 & 209.3 & 319.9 & 3.5 & 48.4 & 78.0 & 116.3 & 192.0 & 245.3 \\
\hline $\mathrm{K}(\mathrm{ppm})$ & 0.0 & 2.5 & 3.9 & 8.0 & 26.0 & 118.8 & 0.0 & 2.2 & 3.3 & 5.4 & 14.9 & 60.0 \\
\hline $\mathrm{Mg}(\mathrm{ppm})$ & 5.7 & 32.4 & 49.9 & 83.7 & 200.9 & 485.8 & 5.7 & 29.6 & 44.4 & 68.4 & 124.4 & 217.4 \\
\hline $\mathrm{Na}(\mathrm{ppm})$ & 12.2 & 31.5 & 56.1 & 129.3 & 500.4 & 1229.0 & 12.2 & 29.4 & 46.2 & 78.8 & 214.4 & 550.0 \\
\hline B (ppm) & 0.0 & 0.8 & 1.1 & 1.8 & 3.9 & 64.0 & 0.0 & 0.7 & 1.0 & 1.5 & 2.8 & 6.0 \\
\hline $\mathrm{Br}(\mathrm{ppm})$ & 0.1 & 0.3 & 0.8 & 1.6 & 4.8 & 9.7 & 0.1 & 0.3 & 0.7 & 1.4 & 3.2 & 5.3 \\
\hline $\mathrm{Al}(\mathrm{ppb})$ & 0.0 & 30.0 & 50.0 & 90.0 & 462.0 & 1710.0 & 0.0 & 30.0 & 40.0 & 90.0 & 388.5 & 1710.0 \\
\hline As (ppb) & 0.4 & 2.4 & 4.7 & 13.5 & 109.6 & 228.4 & 0.4 & 2.1 & 4.4 & 13.3 & 107.9 & 183.7 \\
\hline $\mathrm{Ba}(\mathrm{ppb})$ & 23.9 & 72.9 & 98.9 & 135.1 & 192.7 & 360.5 & 24.3 & 75.4 & 101.7 & 133.1 & 174.9 & 210.1 \\
\hline $\mathrm{Cd}(\mathrm{ppb})$ & 0.1 & 0.1 & 0.5 & 1.1 & 2.0 & 2.8 & 0.1 & 0.1 & 0.6 & 1.1 & 2.1 & 2.8 \\
\hline $\mathrm{Fe}(\mathrm{ppb})$ & 0.0 & 0.0 & 110.0 & 400.0 & 1102.0 & 4070.0 & 0.0 & 0.0 & 120.0 & 407.5 & 1018.0 & 4070.0 \\
\hline $\mathrm{Li}(\mathrm{ppb})$ & 0.7 & 5.3 & 16.1 & 27.7 & 93.0 & 168.3 & 0.7 & 4.5 & 12.4 & 23.0 & 50.4 & 150.0 \\
\hline $\mathrm{Mn}(\mathrm{ppb})$ & 0.0 & 0.1 & 10.0 & 80.0 & 290.0 & 650.0 & 0.0 & 0.1 & 15.0 & 70.0 & 228.5 & 650.0 \\
\hline Mo (ppb) & 0.1 & 0.6 & 1.4 & 2.6 & 5.2 & 16.6 & 0.1 & 0.5 & 1.4 & 2.3 & 5.1 & 10.0 \\
\hline $\mathrm{Ni}(\mathrm{ppb})$ & 0.7 & 0.7 & 2.8 & 7.1 & 16.5 & 91.5 & 0.7 & 0.7 & 2.8 & 6.3 & 15.7 & 91.5 \\
\hline $\mathrm{P}(\mathrm{ppb})$ & 0.0 & 20.0 & 30.0 & 80.0 & 202.0 & 1810.0 & 0.0 & 20.0 & 30.0 & 77.5 & 343.0 & 1810.0 \\
\hline $\mathrm{Rb}(\mathrm{ppb})$ & 0.4 & 5.7 & 10.6 & 28.3 & 121.1 & 398.0 & 0.7 & 5.1 & 9.8 & 20.9 & 101.7 & 205.6 \\
\hline $\mathrm{Se}(\mathrm{ppb})$ & 0.1 & 0.1 & 0.3 & 2.9 & 9.4 & 41.1 & 0.1 & 0.1 & 0.1 & 2.0 & 5.7 & 10.7 \\
\hline $\mathrm{Si}(\mathrm{ppm})$ & 0.1 & 8.1 & 9.6 & 11.6 & 20.4 & 38.8 & 0.1 & 8.0 & 9.4 & 11.0 & 17.6 & 38.8 \\
\hline $\mathrm{Sr}(\mathrm{ppb})$ & 0.0 & 447.9 & 674.1 & 1040.0 & 1908.0 & 3541.7 & 0.0 & 369.6 & 620.0 & 875.8 & 1600.6 & 2140.0 \\
\hline $\mathrm{U}(\mathrm{ppb})$ & 0.7 & 0.7 & 1.7 & 3.3 & 8.7 & 13.0 & 0.7 & 0.7 & 1.5 & 2.4 & 4.7 & 10.1 \\
\hline $\mathrm{Zn}(\mathrm{ppb})$ & 0.7 & 2.2 & 9.3 & 16.2 & 48.8 & 166.4 & 0.7 & 2.0 & 9.3 & 16.6 & 57.7 & 166.4 \\
\hline
\end{tabular}


Although $\mathrm{NO}_{3}$ and $\mathrm{Cl}$ were used in this study to remove contaminated samples, some other contaminated samples may be present in the data set that cannot be identified by these two criteria. The use of $\mathrm{NO}_{3}$ can be useful in identifying water sources contaminated by factors such as contaminated wastewater from agriculture, livestock, residential and industrial effluents (Amiri et al. 2021b). Weak correlation of $\mathrm{NO}_{3}$ and $\mathrm{Cl}$ with the main chemical compounds (include $\mathrm{SO}_{4}, \mathrm{~F}, \mathrm{As}, \mathrm{Fe}, \mathrm{Mn}$ ) indicates that the use of this criterion in the pre-selection step cannot cause a significant change in the calculation of NBLs (Parrone et al. 2019).

\section{Calculating the NBLs}

342 NBL of chemical compounds of groundwater were calculated using two Iterative $2 \sigma$ and CDF 343 methods (Table 3). Examining the efficiency of each of these two methods in creating a normal 344 distribution of the chemical variables shows that out of 19 selected variables, one or both 345 methods can provide a normal distribution for 15 variables. As shown in Table 3, these 15 346 variables have a $t$-statistic value less than the $t$-crit. This means their normal distribution and the 347 efficiency of the methods used to calculate the NBLs. Of course, it should be noted that in some 348 cases, only one method provides a good result. In other words, the efficiency of each of these methods in calculating the NBL is a function of the data frequency distribution.

Based on the results, $\mathrm{NBL}$ of $\mathrm{Cl}, \mathrm{HCO}_{3}+\mathrm{CO}_{3}, \mathrm{Al}$, and $\mathrm{Mn}$ cannot be calculated using these two methods. For these elements, the $t$-statistic value is greater than the $t$-crit. In other words, 352 since the condition for accepting the computational value as NBL is the normal distribution of 353 the data remaining after the calculation, these methods cannot provide acceptable results for $354 \mathrm{NBL}$ of $\mathrm{Cl}, \mathrm{HCO}_{3}+\mathrm{CO}_{3}, \mathrm{Al}$, and $\mathrm{Mn}$. This condition is due to the highly skewed distribution of 355 data. In cases where the distance between the minimum and maximum concentrations of chemical components is very large, these methods do not provide a good result for the NBL

357 calculation because in this case, the data mode is too large and this eliminates a large number of 358 samples to establish a normal distribution. (Bulut et al. 2020).

NBLs calculated by statistical approaches (i.e. Iterative $2 \sigma$ and CDF) show that in cases that 360 only one method leads to a normal distribution of the remaining data, the upper limit of the 361 calculated background values for the data set can be considered as the NBL of that variable 362 (Table 4). Conversely, if both methods have a lower $t$-statistic than the $t$-crit. (i.e. normal 363 distribution), the maximum value of the upper limit of these two methods can be considered as 
364 the final NBL (Parrone et al. 2019). As mentioned earlier, the NBL values of the variables $\mathrm{Cl}$, $365 \mathrm{HCO}_{3}+\mathrm{CO}_{3}, \mathrm{Al}$, and $\mathrm{Mn}$ cannot be calculated using Iterative $2 \sigma$ and $\mathrm{CDF}$ methods. Therefore, 366 for these elements, the deterministic method (i.e. 95th percentile of remaining data) can be used 367 as NBL (Urresti-Estala et al. 2013; Bulut et al. 2020). It should be noted, however, that when the 368 frequency distribution curve is skewed, or in other words has many outliers, estimating the NBL 369 as a definite percentile may sometimes yield different results compared to other methods 370 (Parrone et al. 2019).

372 Table 3 General results of using Iterative $2 \sigma$ and CDF methods in calculating the NBLs.

\begin{tabular}{ccccccccc}
\hline \multirow{2}{*}{ Parameter } & \multicolumn{3}{c}{ Iterative $2 \sigma$} & & \multicolumn{3}{c}{ CDF } \\
\cline { 2 - 5 } \cline { 6 - 8 } & $\mathrm{TV}$ & $t$-crit. & $t$ - statistic* & & $\mathrm{TV}$ & $t$-crit. & $t$ - statistic \\
\hline $\mathrm{EC}(\mu \mathrm{S} / \mathrm{cm})$ & 1086.1 & 0.086 & 0.07 & & 1196.1 & 0.075 & 0.06 \\
$\mathrm{SO}_{4}(\mathrm{ppm})$ & 88.1 & 0.093 & 0.061 & & 131.1 & 0.074 & 0.063 \\
$\mathrm{~F}(\mathrm{ppm})$ & 0.9 & 0.086 & 0.024 & & 1 & 0.075 & 0.028 \\
$\mathrm{Cl}(\mathrm{ppm})$ & 45.1 & 0.089 & 0.117 & & 60.7 & 0.075 & 0.097 \\
$\mathrm{HCO}_{3}+\mathrm{CO}_{3}(\mathrm{ppm})$ & 592.6 & 0.080 & 0.122 & & 619.5 & 0.075 & 0.119 \\
$\mathrm{Ca}(\mathrm{ppm})$ & 126.9 & 0.084 & 0.084 & & 145.1 & 0.076 & 0.074 \\
$\mathrm{~K}(\mathrm{ppm})$ & 4.3 & 0.92 & 0.9 & & 5.9 & 0.076 & 0.052 \\
$\mathrm{Mg}(\mathrm{ppm})$ & 59.5 & 0.90 & 0.082 & & 76.4 & 0.075 & 0.068 \\
$\mathrm{Na}(\mathrm{ppm})$ & 61.7 & 0.092 & 0.083 & & 84.3 & 0.075 & 0.094 \\
$\mathrm{~B}(\mathrm{ppm})$ & 1.8 & 0.082 & 0.037 & & 1.9 & 0.075 & 0.036 \\
$\mathrm{Br}(\mathrm{ppm})$ & 0.8 & 0.098 & 0.019 & & 1.5 & 0.073 & 0.087 \\
$\mathrm{Al}(\mathrm{ppb})$ & 79.4 & 0.078 & 0.172 & & 79.4 & 0.078 & 0.172 \\
$\mathrm{As}(\mathrm{ppb})$ & 6.2 & 0.097 & 0.101 & & 9.6 & 0.074 & 0.068 \\
$\mathrm{Ba}(\mathrm{ppb})$ & 157.9 & 0.081 & 0.074 & & 169.1 & 0.075 & 0.053 \\
$\mathrm{Fe}(\mathrm{ppb})$ & 611.6 & 0.104 & 0.097 & & 558.4 & 0.099 & 0.068 \\
$\mathrm{Li}(\mathrm{ppb})$ & 30.3 & 0.079 & 0.067 & & 28.3 & 0.075 & 0.072 \\
$\mathrm{Mn}(\mathrm{ppb})$ & 72.2 & 0.10 & 0.238 & & 104.6 & 0.082 & 0.186 \\
$\mathrm{Si}(\mathrm{ppm})$ & 12.1 & 0.084 & 0.047 & & 14 & 0.077 & 0.084 \\
$\mathrm{Sr}(\mathrm{ppb})$ & 996.1 & 0.096 & 0.056 & & 1132.7 & 0.085 & 0.054 \\
\hline
\end{tabular}

* Lilliefors test statistic $(\alpha=0.05)$

374 In this study, despite calculating the NBL of many groundwater chemical variables, an 375 attempt has been made to focus more on some of them. These elements include $\mathrm{SO}_{4}, \mathrm{~F}, \mathrm{As}, \mathrm{Fe}$, 376 and Mn. The selection of these elements is based on previous studies by authors in this area and 377 does not mean that other chemical components are insignificant. 
379 Table 4 Calculated NBLs by statistical (i.e. Iterative $2 \sigma$ and CDF) and deterministic (95th 380 percentile) approaches

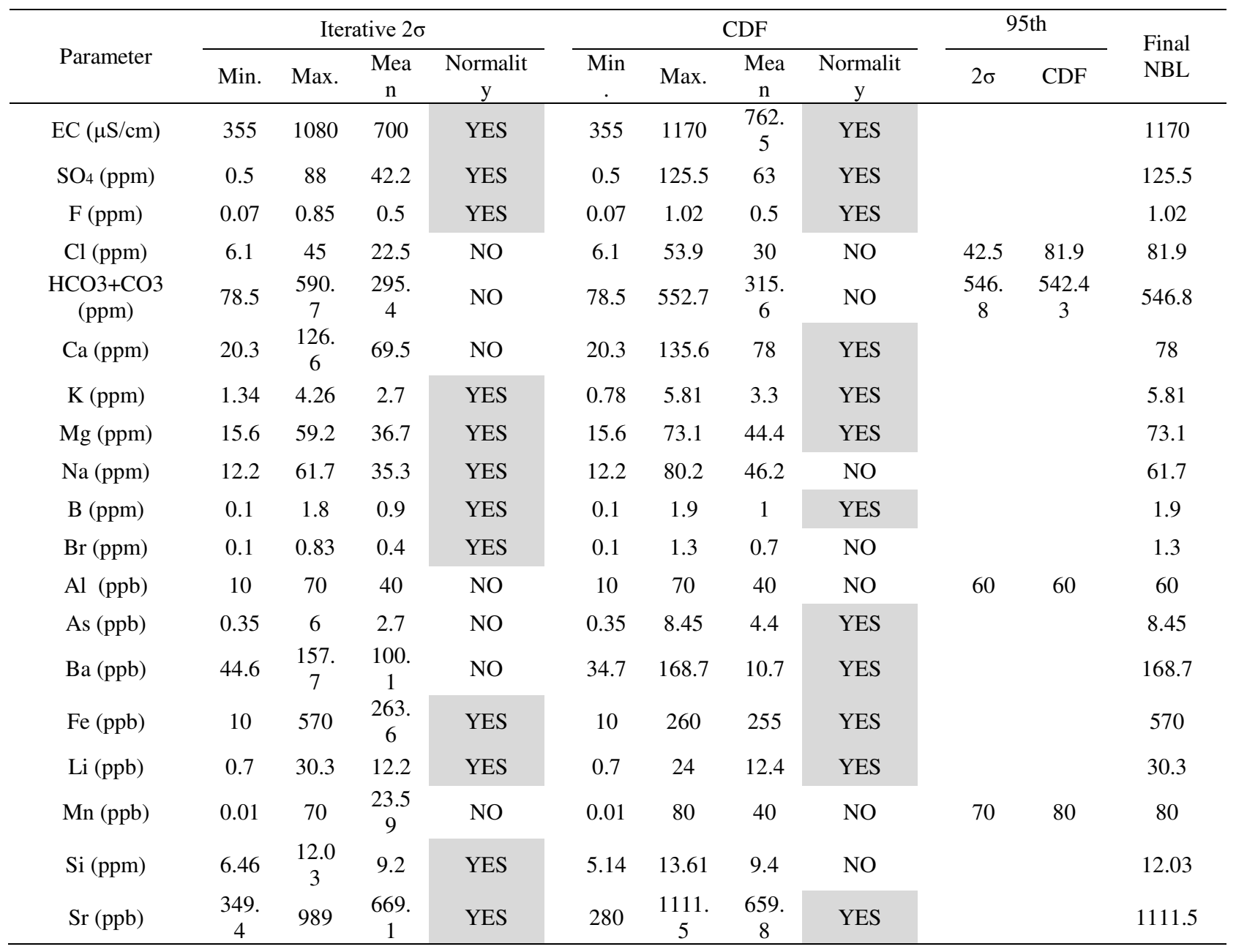

Hydrogeochemical analysis of this aquifer shows that $\mathrm{Ca}-\mathrm{HCO}_{3} / \mathrm{SO}_{4}$ is the predominant

383 groundwater facies, which indicates the general fresh groundwater. However, the UA may in

384 some places be affected by salinity or freshening due to the change of seasons and changes in the

385 aquifer recharge. In some places, mechanisms such as cation exchange reactions between water

386 and aquifer solid materials, mixing with saline groundwater derived from dilute brine, and

387 possibly dissolving salts in the unsaturated zone can cause salinization and increase the 388 concentration of some major elements such as $\mathrm{Na}, \mathrm{Cl}$, and $\mathrm{SO}_{4}$ in some samples.

389 Calculation of $\mathrm{NBL}$ of $\mathrm{SO}_{4}$ as a chemical variable that can be of human and natural origin 390 shows that both Iterative $2 \sigma$ and CDF methods can provide a normal distribution of background 391 values (Table 4). Based on the results of the Kolmogorov-Smirnov test, as the computed p-value 
392 (0.618) is greater than the significance level $(\alpha=0.05)$, the NBL calculated by the Iterative $2 \sigma$ 393 approach for $\mathrm{SO}_{4}$ follows a Normal distribution (Fig. 3).

394 The results show that in the Iterative $2 \sigma$ method, the computational NBL is between 0.5 and $39588 \mathrm{ppm}$ (with an average of $42.2 \mathrm{ppm}$ ). On the other hand, in the CDF method, NBL has a higher 396 upper limit (125.5 ppm) and mean (63 ppm) compared to the first method. However, based on 397 the results of the Kolmogorov-Smirnov test, as the computed p-value (0.42) is greater than the 398 significance level $(\alpha=0.05)$, the NBL calculated by the CDF method for $\mathrm{SO}_{4}$ follows a Normal 399 distribution (Fig. 3). Therefore, given that both methods have a lower $t$-statistic than the $t$-crit., 400 the upper limit of the CDF method (125.5 ppm) can be considered as the final NBL. In Fig.3, the 401 NBL calculated for $\mathrm{SO}_{4}$ by Iterative $2 \sigma$ and $\mathrm{CDF}$ methods as well as distribution fitting on 402 background values are shown.
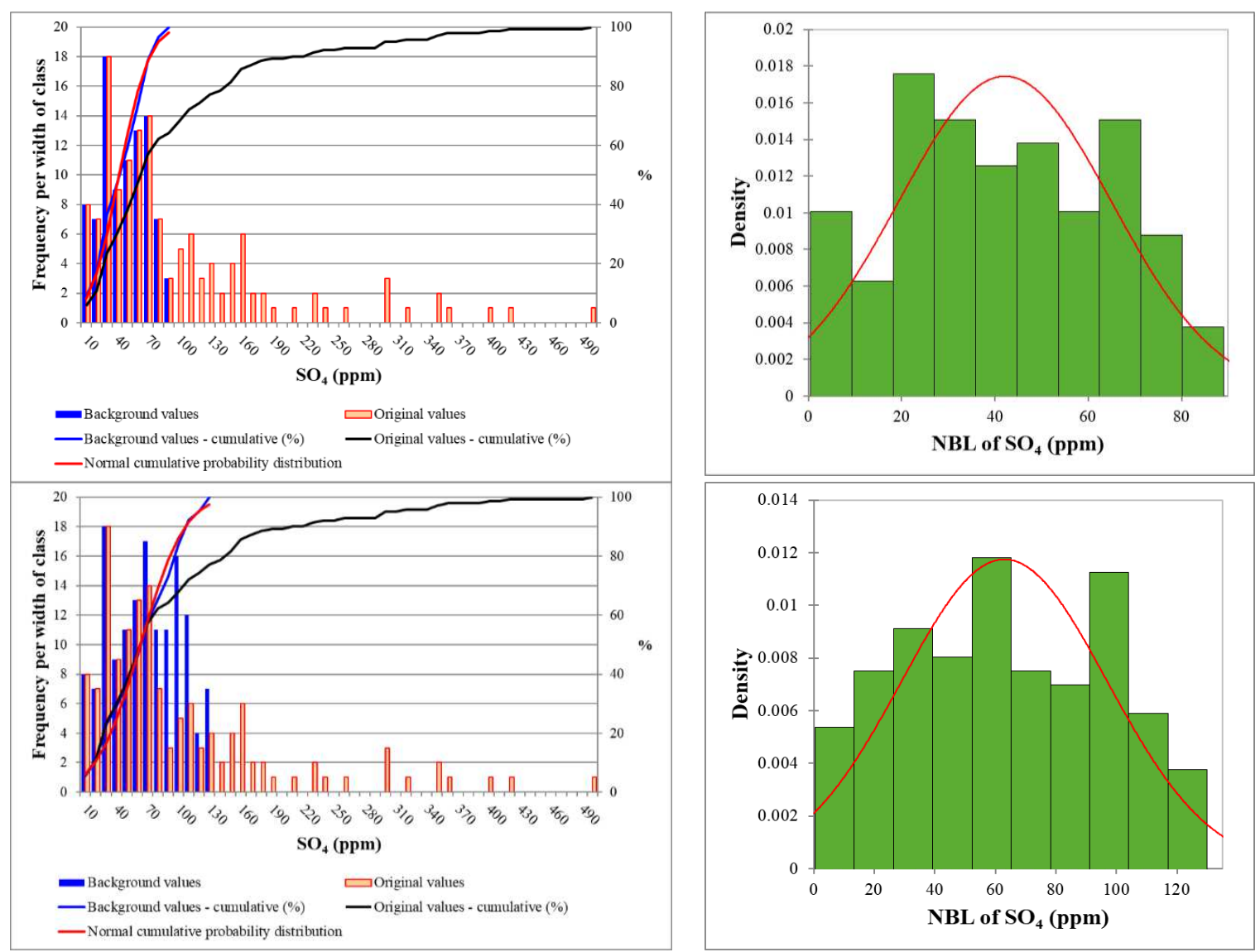

Fig. 3 NBL calculated for $\mathrm{SO}_{4}$ by Iterative $2 \sigma$ (upper) and $\mathrm{CDF}$ (lower) methods.

As shown in Table 5, the NBL calculated for $\mathrm{SO}_{4}$ is less than the reference values (REF). 
407 has a high concentration in some samples if we consider only the role of natural/geochemical 408 activities, this anion will have concentrations lower than REF and will not pose a risk to human 409 health.

Table 5 Comparison of REF, NBL, and TV for studied variables

\begin{tabular}{cccc}
\hline Parameter & REF & NBL & TV \\
\hline $\mathrm{EC}(\mu \mathrm{p} / \mathrm{cm})$ & n.d. & 1170 & 1086.1 \\
$\mathrm{SO}_{4}(\mathrm{ppm})$ & $400^{\mathrm{a}}, 250^{\mathrm{b}}$ & 125.5 & 88.1 \\
$\mathrm{~F}(\mathrm{ppm})$ & $1.5^{\mathrm{a}}, 2^{\mathrm{b}}$ & 1.02 & 0.9 \\
$\mathrm{Cl}(\mathrm{ppm})$ & $250^{\mathrm{a}, \mathrm{b}}$ & 81.9 & 45.1 \\
$\mathrm{HCO}_{3}+\mathrm{CO} 3(\mathrm{ppm})$ & n.d. & 546.8 & 592.6 \\
$\mathrm{Ca}(\mathrm{ppm})$ & $300^{\mathrm{a}}$ & 78 & 145.1 \\
$\mathrm{~K}(\mathrm{ppm})$ & $12^{\mathrm{a}}$ & 5.81 & 4.3 \\
$\mathrm{Mg}(\mathrm{ppm})$ & $30^{\mathrm{a}}$ & 73.1 & 76.4 \\
$\mathrm{Na}(\mathrm{ppm})$ & $250^{\mathrm{a}}$ & 61.7 & 61.7 \\
$\mathrm{~B}(\mathrm{ppm})$ & $1^{\mathrm{c}}$ & 1.9 & 1.9 \\
$\mathrm{Br}(\mathrm{ppm})$ & n.d. & 1.3 & 0.8 \\
$\mathrm{Al}(\mathrm{ppb})$ & $50^{\mathrm{b}}$ & 60 & 79.4 \\
$\mathrm{As}(\mathrm{ppb})$ & $10^{\mathrm{b}}$ & 8.45 & 9.6 \\
$\mathrm{Ba}(\mathrm{ppb})$ & $2000^{\mathrm{b}}$ & 168.7 & 169.1 \\
$\mathrm{Fe}(\mathrm{ppb})$ & $200^{\mathrm{b}}$ & 570 & 558.4 \\
$\mathrm{Li}(\mathrm{ppb})$ & n.d. & 30.3 & 30.3 \\
$\mathrm{Mn}(\mathrm{ppb})$ & 50 & 80 & 72.2 \\
$\mathrm{Si}(\mathrm{ppm})$ & n.d. & 12.03 & 12.1 \\
$\mathrm{Sr}(\mathrm{ppb})$ & n.d. & 1111.5 & 1132.7 \\
\hline 1$)^{\mathrm{b}}(\mathrm{EPA} 2011),{ }^{\mathrm{c}}($ Bulut et al. 2020$)$, n.d: not defined
\end{tabular}

412 The study of this area shows that intensive agricultural activities can increase the 413 concentration of some compounds due to the use of agricultural fertilizers. The results of 414 geophysical studies show that with increasing depth, one can see an increase in electrical 415 resistance, which can be interpreted as a relative decrease in solute concentration. Therefore, 416 most samples with high levels of solutes are affected by surface currents (such as agricultural 417 return water and effluents of residential and industrial units). These changes have also been 418 confirmed by isotopic and geochemical studies (Amiri et al. 2017, 2016).

419 Amiri and Berndtsson (2020) showed that by studying the concentration of $\mathrm{F}$ in 58 and 84 420 groundwater samples in both wet and dry seasons, 15 and $23 \%$ of the samples had a F 421 concentration higher than the standard drinking water recommended by WHO (2011). The 422 results show that high concentrations of $\mathrm{F}$ are often measured in shallow wells, which may be 
423 due to human activities such as industrial and agricultural effluents. On the other hand, the 424 interaction between groundwater and geological formations also plays an important role in 425 controlling the F content in groundwater. Some of these high F samples are located in the 426 vicinity of volcanic rocks. Besides, they showed that children at risk for non-carcinogenic 427 diseases due to groundwater consumption had high $\mathrm{F}$ concentrations.

428 Therefore, considering the importance of studying the role of human and natural factors in 429 changing the F concentration in this part of the Urmia aquifer, this study has tried to calculate the $430 \mathrm{NBL}$ of this anion. The results of NBL of $\mathrm{F}$ show that similar to $\mathrm{SO}_{4}$, both Iterative $2 \sigma$ and CDF 431 methods can provide a normal distribution of background values (Table 4). The results of the 432 Kolmogorov-Smirnov test indicate that as the computed p-value (0.702) is greater than the 433 significance level $(\alpha=0.05)$, the NBL calculated by the Iterative $2 \sigma$ approach for $F$ follows a 434 Normal distribution (Fig. 4).
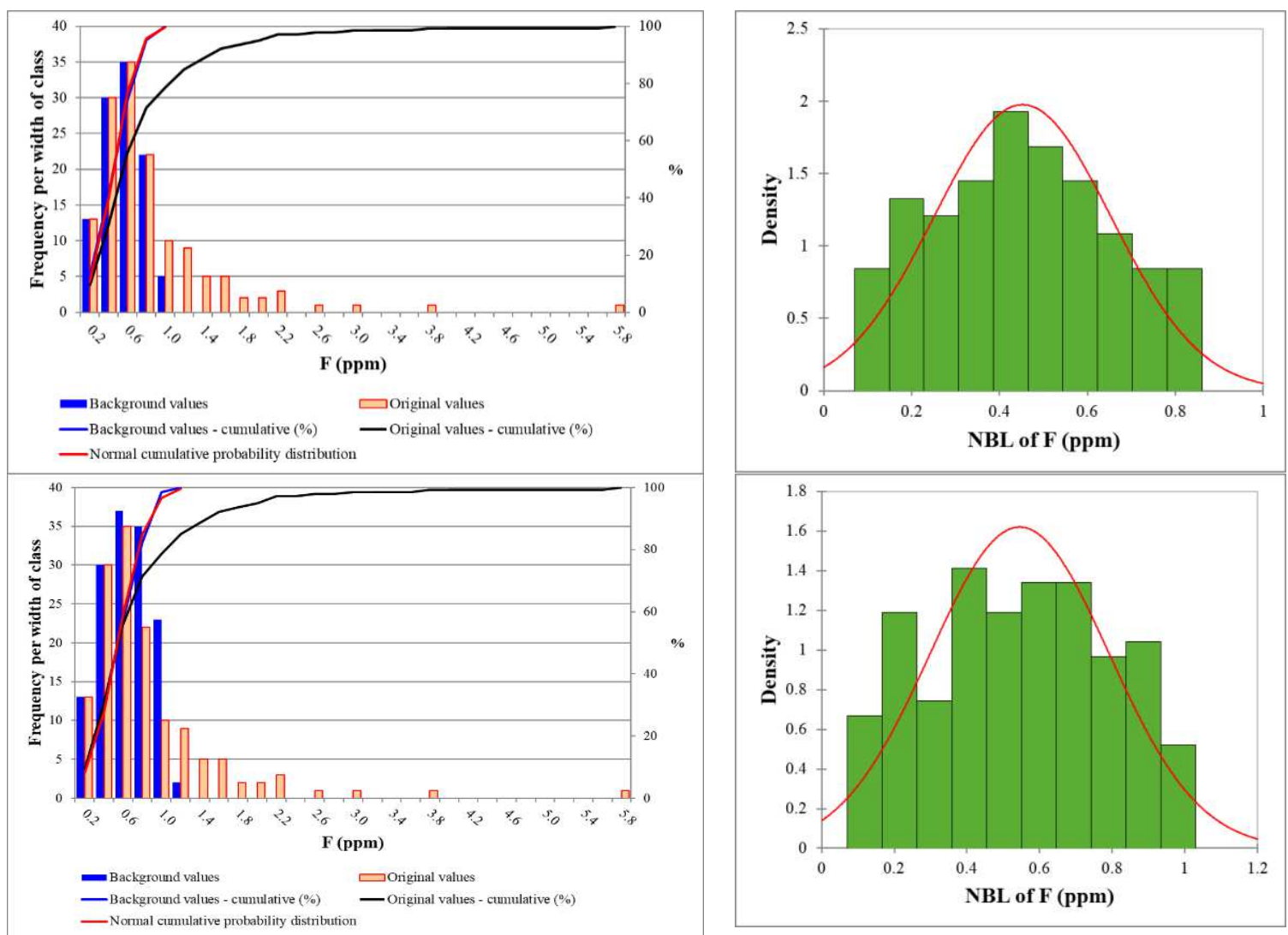

Fig. 4 NBL calculated for F by Iterative $2 \sigma$ (upper) and CDF (lower) methods.

437 In the Iterative $2 \sigma$ method, the NBL varies between 0.07 and $0.85 \mathrm{ppm}$ (with an average of $4380.5 \mathrm{ppm})$. On the other hand, in the CDF method, NBL has a higher upper limit (1.02 ppm) 
compared to the first method. However, the Kolmogorov-Smirnov test demonstrates the normal 440 distribution for NBL calculated by the CDF method, as the computed p-value (0.77) is greater 441 than the significance level $(\alpha=0.05)$ (Fig. 4). Therefore, given that both methods have a lower $t$ 442 statistic than the $t$-crit. The upper limit of the CDF method (1.02 ppm) can be considered as the 443 final NBL. In Fig. 4, the NBL calculated for F by Iterative $2 \sigma$ and CDF methods as well as 444 distribution fitting on background values are shown.

445 As shown in Table 5, the NBL calculated for $\mathrm{F}$ is less than the REF value. Therefore, 446 although the concentration of $\mathrm{F}$ in some samples is higher than international standards, the 447 results show that natural/geochemical factors cannot increase the concentration of $\mathrm{F}$ above the 448 recommended value for drinking. Therefore, any increase above $1.02 \mathrm{ppm}$ could be due to 449 human contamination.

450 Sohrabi et al. (2020) examined groundwater quality in UA by focusing on potentially toxic 451 elements. The results showed that some elements such as $\mathrm{Fe}, \mathrm{Ba}$, and $\mathrm{Al}$ have the highest 452 concentrations compared to other elements. However, some elements such as $\mathrm{Cr}$ and $\mathrm{Cd}$ also 453 have the lowest concentrations among these elements. Besides, As, as one of the most important 454 elements that can have irreversible effects on human health, in some samples has a concentration 455 higher than the value recommended by WHO (2011). This element can be at an alarming level 456 and can pose risks such as carcinogenic and non-carcinogenic diseases in children and adults. 457 According to the results, the most important factors controlling the concentration of As in these 458 waters is the reductive dissolution of $\mathrm{Fe}$ (hydro)oxides and clay minerals. Also, the use of 459 agricultural fertilizers, especially phosphate fertilizers, can play a role in reducing the concentration of As due to an increase in its adsorption rate.

461 Therefore, the determination of NBL of As can be of great help in identifying human and 462 natural factors controlling its concentration, as well as performing water resources management 463 measures and preventing health problems through drinking water consumption. On the other 464 hand, due to the role of Fe and the close relationship of this element with $\mathrm{Mn}$ and its high 465 concentration in groundwater sources, the NBL determination of these two elements has received 466 more attention compared to other chemical compounds.

467 Calculation of NBL of As in these groundwater samples shows that only the CDF method 468 can provide a normal distribution of background values (Table 4). In the Iterative $2 \sigma$ method, the 469 NBL varies between 0.35 and 6 ppm (average $2.7 \mathrm{ppm}$ ). On the other hand, in the CDF method, 
470 NBL has a higher upper limit $(8.45 \mathrm{ppm})$ and mean $(4.4 \mathrm{ppm})$ value compared to the first 471 method. However, as the computed p-value (0.288) is greater than the significance level $472(\alpha=0.05)$, the normality test verifies the normal distribution of NBL calculated by the CDF 473 method for As. Therefore, given that the CDF method has a lower $t$-statistic than the $t$-crit., the 474 upper limit of the CDF method $(8.45 \mathrm{ppm})$ can be considered as the final NBL. Fig. 5 shows the 475 NBL calculated for As by Iterative $2 \sigma$ and CDF methods as well as distribution fitting on 476 background values.

477
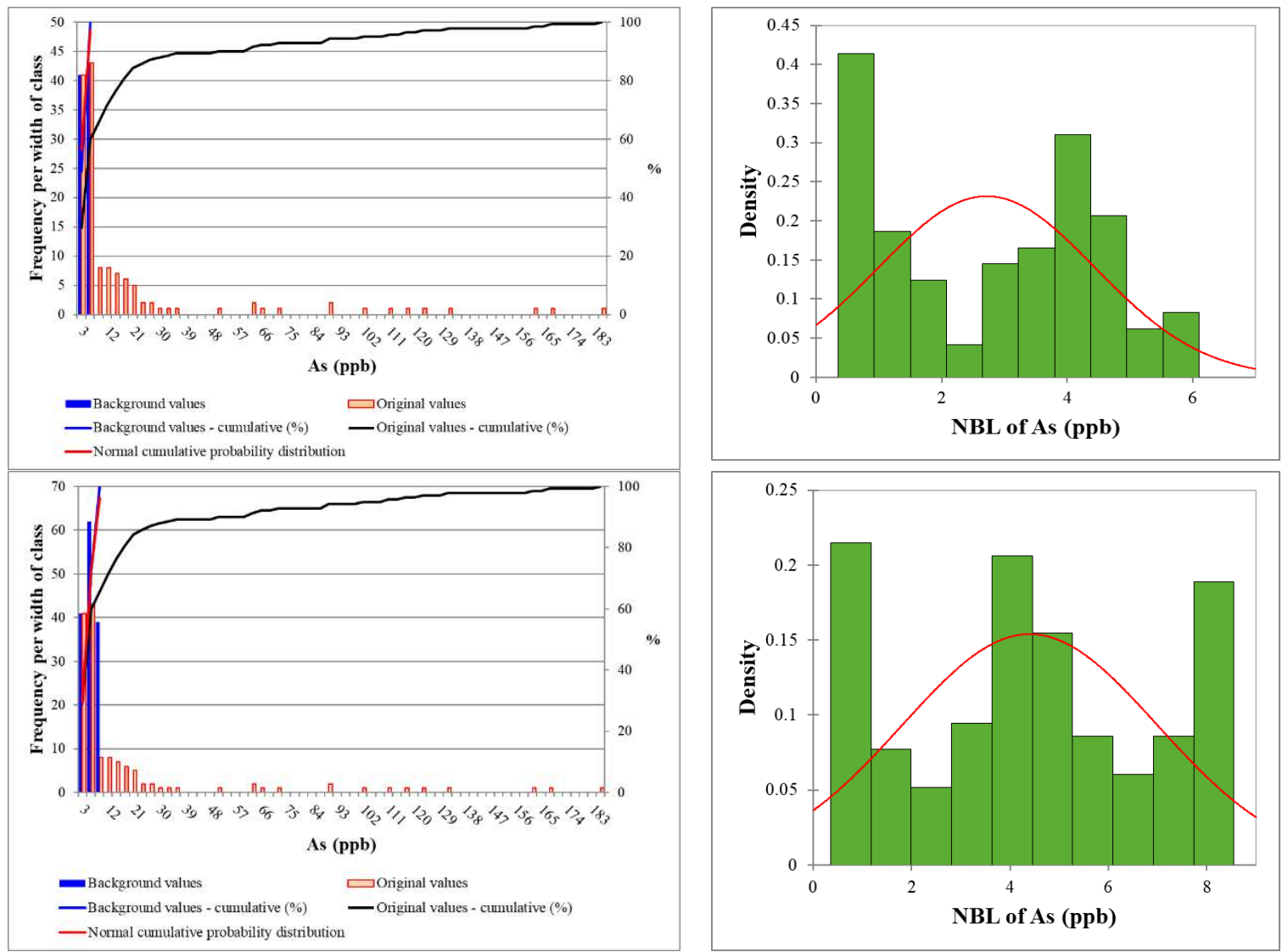

Fig. 5 NBL calculated for As by Iterative $2 \sigma$ (upper) and CDF (lower) methods.

The NBL calculated for As is less than its REF value (Table 5). Therefore, although the concentration of As in some samples is higher than international standards, the results show that natural/geochemical factors cannot increase the concentration of As above the recommended value for drinking. Therefore, any increase greater than $8.45 \mathrm{ppm}$ could be due to human effects.

Based on the computational NBL for Fe, both Iterative $2 \sigma$ and CDF methods can provide the normal distribution of background values (Table 4). In the Iterative $2 \sigma$ approach, as the 
computed $p$-value $(0.462)$ is greater than the significance level $(\alpha=0.05)$, the NBL calculated by 486 this method for Fe follows a Normal distribution. The results show that in the Iterative $2 \sigma$ 487 method, the computational NBL changes between 10 and $570 \mathrm{ppm}$ (with an average of 263.6 488 ppm). On the other hand, in the CDF method, NBL has a lower upper limit (260 ppm) and mean 489 (255 ppm) values compared to the first method. However, as the computed p-value (0.806) is 490 greater than the significance level $(\alpha=0.05)$, the NBL calculated by the Iterative $2 \sigma$ approach for 491 Fe follows a Normal distribution (Fig. 6).
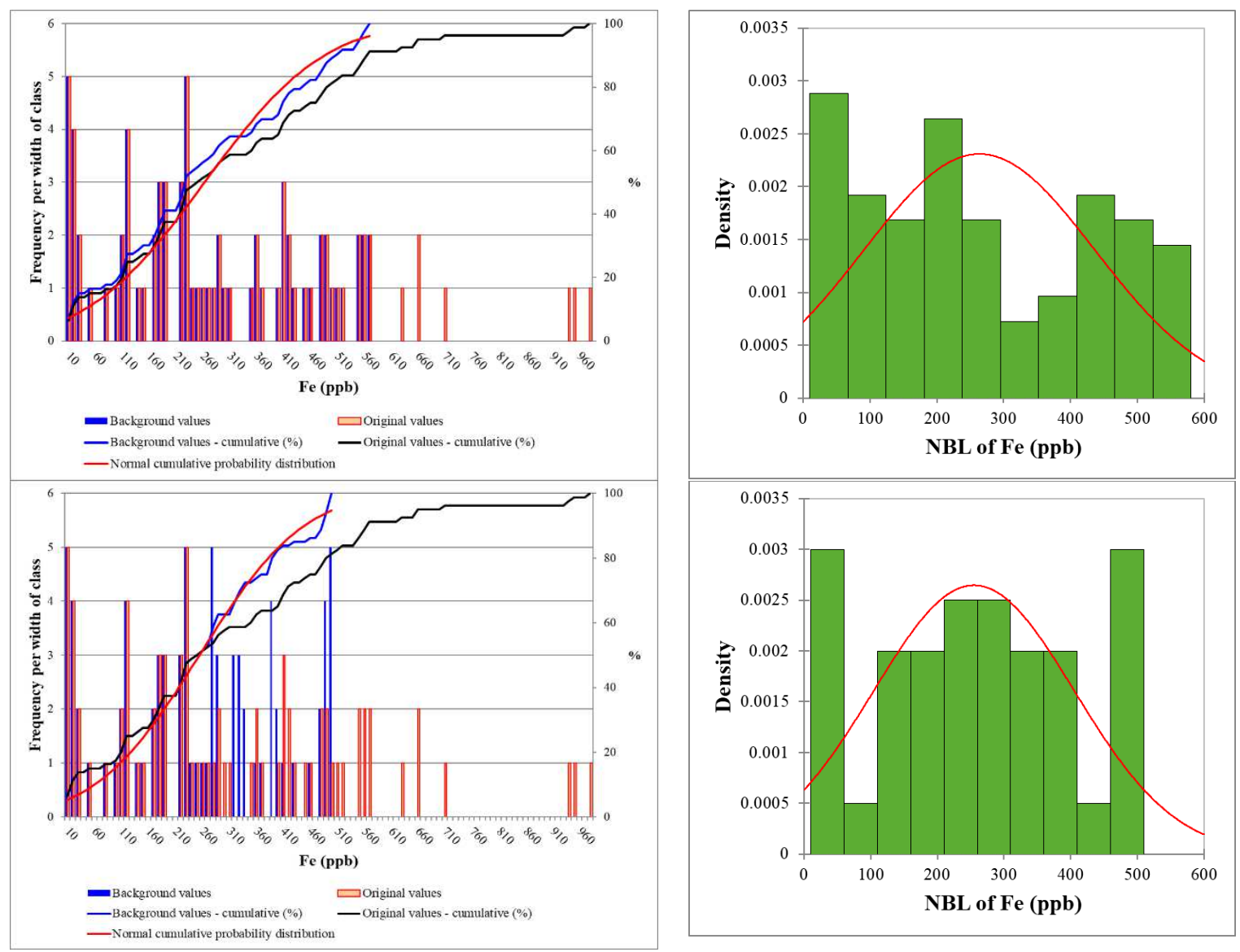

492 Fig. 6 NBL calculated for Fe by Iterative $2 \sigma$ (upper) and CDF (lower) methods.

Therefore, given that both methods have a lower $t$-statistic than the $t$-crit., the upper limit 495 of the Iterative $2 \sigma$ method (570 ppm) can be considered as the final NBL. Figure 6 shows the 496 NBL calculated for Fe by Iterative $2 \sigma$ and CDF methods as well as distribution fitting on 497 background values. 
As shown in Table 5, the NBL calculated for iron is less than the REF value. The results show that natural/geochemical factors cannot increase the concentration of Fe above the recommended value for drinking.

Calculation of NBL of $\mathrm{Mn}$ as an associated element influencing the adsorption and desorption mechanism of $\mathrm{Fe}$ and arsenic shows that none of the Iterative $2 \sigma$ and CDF methods are suitable for calculating the NBL of this element because the remaining data do not follow the normal distribution. Based on the normality test, as the computed p-values for both Iterative $2 \sigma$ and CDF methods (0.0002 and 0.001, respectively) are lower than the significance level $(\alpha=0.05)$, the NBL calculated by these methods for Mn do not follow a normal distribution.

507 Under such circumstances, the use of the 95th percentile of the remaining data (80 ppm) can be 508 considered as the NBL of Mn (Table 4). Figure 7 shows the NBL calculated for Mn by Iterative $5092 \sigma$ and CDF methods as well as distribution fitting on background values. The NBL of Mn is 510 greater than the REF value (Table 5). Therefore, natural geochemical factors can increase the 511 concentration of this element so much that it is not suitable for consumption.
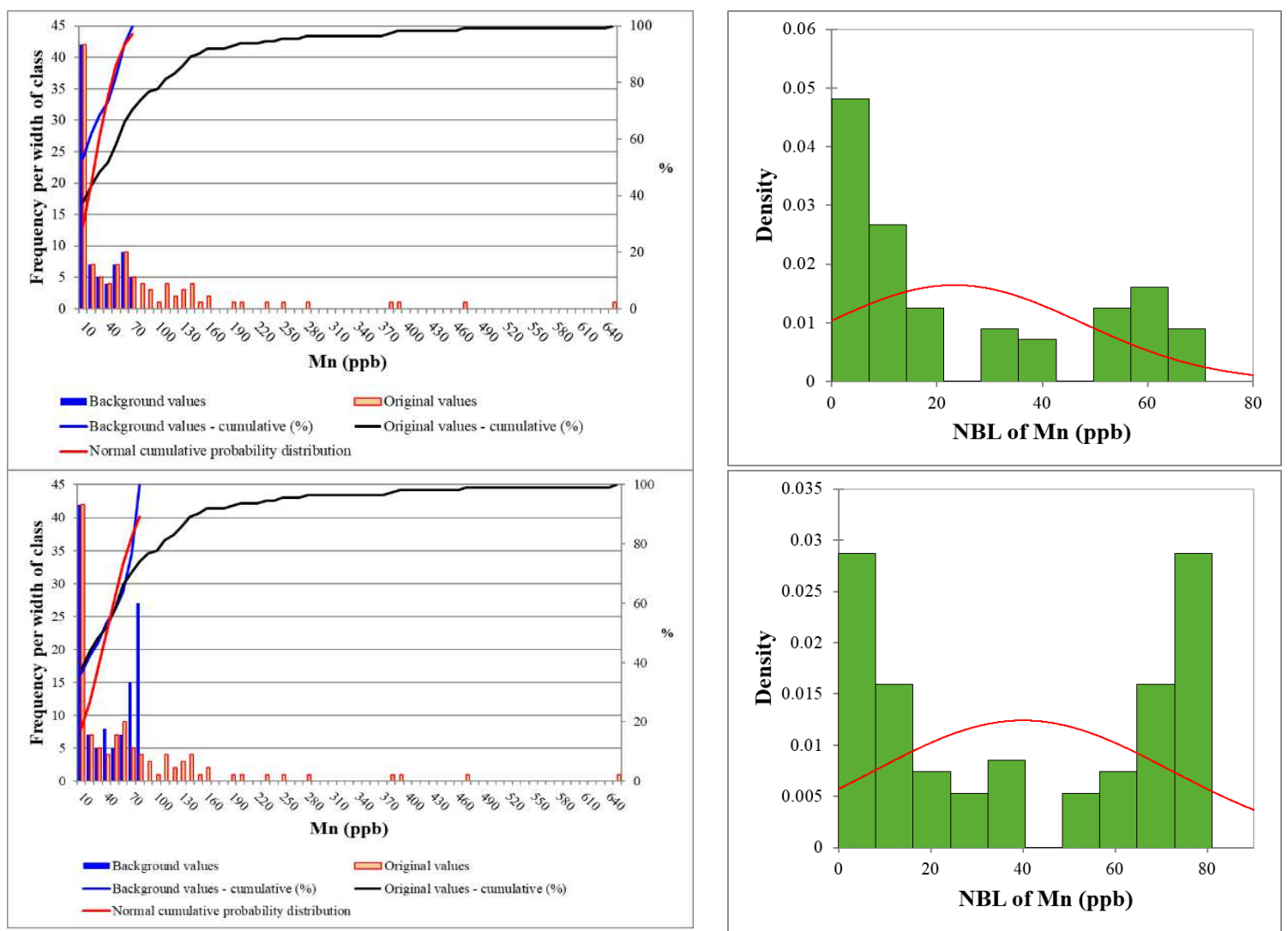

513 Fig. 7 NBL calculated for Mn by Iterative $2 \sigma$ (upper) and CDF (lower) methods. 
Results of NBL calculation for other chemical compounds including $\mathrm{EC}, \mathrm{Cl}, \mathrm{HCO}_{3}+\mathrm{CO}_{3}, \mathrm{Ca}$,

$515 \mathrm{~K}, \mathrm{Mg}, \mathrm{Na}, \mathrm{B}, \mathrm{Br}, \mathrm{Al}, \mathrm{Ba}, \mathrm{Li}, \mathrm{Si}$, and $\mathrm{Sr}$ is provided in Tables 4, 5, and 6 and Supplementary

516 Figs. S1-S14. These components, especially major ions, are generally controlled by natural

517 factors and despite the actions taken in the pre-selection stage, in some cases, they are also

518 affected by human factors. However, the NBLs calculated for these variables can be of great help

519 in identifying natural and geochemical values and human impacts.

\section{Conclusions}

522 In this study, using statistical and graphical methods, the NBL of chemical compounds with high 523 background value has been investigated. The number of 175 original samples was reduced to 140 524 in the pre-selection step based on the concentration of $\mathrm{NO}_{3}$ and $\mathrm{Cl}$. The purpose of this step is to 525 remove samples that may have been contaminated by human activities. Then, the NBL of 19 526 chemical compounds was determined using Iterative $2 \sigma$ and CDF methods. Thus, the NBL of 15 527 compounds was determined using these methods because the remaining data had a normal 528 distribution and, besides, the $t$-statistic was lower than $t$-crit. Given that the condition for 529 accepting the result obtained by these two statistical methods is the normal distribution of data, 530 the $\mathrm{NBL}$ of the variables $\mathrm{Cl}, \mathrm{HCO}_{3}+\mathrm{CO}_{3}, \mathrm{Al}$, and $\mathrm{Mn}$ cannot be calculated using Iterative $2 \sigma$ and 531 CDF methods. Therefore, the NBL of these elements was determined definitively (i.e. 95th 532 percentile of remaining data). According to previous studies, the importance of components such 533 as $\mathrm{SO}_{4}, \mathrm{~F}, \mathrm{As}, \mathrm{Fe}$, and $\mathrm{Mn}$, their high concentration relative to the REF values, and their role in 534 degrading the quality of water used by residents, has led to more focus on these elements in this 535 study. Results showed that the upper limit of $\mathrm{NBL}$ calculated for $\mathrm{SO}_{4}, \mathrm{~F}, \mathrm{As}, \mathrm{Fe}$ and $\mathrm{Mn}$ is about 536125 ppm, 1 ppm, $8.5 \mathrm{ppb}, 570 \mathrm{ppb}, 80 \mathrm{ppb}$, respectively. Given that a study aimed at determining 537 the NBL of various elements in groundwater has not been conducted in Iran, the results of this 538 study can be a good roadmap for decision-makers and researchers to better manage this aquifer 539 and other water resources in this country with limited freshwater resources.

\section{Acknowledgments}

542 We would like to thank all of the members of the GSI for their kind cooperation that made this 543 research possible. Dr. Peiyue Li is grateful for the support from the National Natural Science 544 Foundation of China (42072286 and 41761144059), the Fundamental Research Funds for the 
545 Central Universities of CHD (300102299301), the Fok Ying Tong Education Foundation

546 (161098), the China Postdoctoral Science Foundation (2015M580804, 2016M590911,

547 2016T090878 and 2017T100719), the Shaanxi Postdoctoral Science Foundation

548 (2015BSHTDZZ09 and 2016BSHTDZZ03), and the Ten Thousand Talent Program

549 (W03070125).

550 Ethical Approval

$551 \quad$ Not applicable

\section{Consent to Participate}

553 Not applicable

554 Consent to Publish

555 Not applicable

556 Authors Contributions

557 Vahab Amiri: Conceptualization, methodology, figures and tables preparation, literature search

558 and evaluation, reviewing and editing of the manuscript.

559 Mohammad Nakhaei: Literature search and evaluation, methodology, reviewing and editing of

560 the manuscript.

561 Razyeh Lak: Literature search and evaluation, reviewing and editing of the manuscript.

562 Peiyue Li: Validation, reviewing and editing of the manuscript.

563 Funding

564 The research leading to these results received funding from Geological Survey of Iran.

\section{Competing Interests}

566 The authors declare that they have no known competing financial interests or personal relationships that could

567 have appeared to influence the work reported in this paper.

568 Availability of data and materials 
The datasets generated during and/or analysed during the current study are available from the corresponding

570 author on reasonable request.

571

\section{References}

573 Almasri MN (2007) Nitrate contamination of groundwater: a conceptual management

574 framework. $\quad$ Environ $\quad$ Impact $\quad$ Assess 27:220-242. https://doi.org/10.1016/j.eiar.2006.11.002

Amiri V, Berndtsson R (2020) Fluoride Occurrence and Human Health Risk from Groundwater Use at the West Coast of Urmia Lake, Iran. Arab J Geosci https://doi.org/10.1007/s12517$\underline{020-05905-7}$

Amiri V, Bhattacharya P, Nakhaei M (2021a) The hydrogeochemical evaluation of groundwater resources and their suitability for agricultural and industrial uses in an arid area of Iran. Groundw Sustain Dev 12:100527. https://doi.org/10.1016/j.gsd.2020.100527

Amiri V, Kamrani S, Ahmad A, Bhattacharya P, Mansoori J (2021b) Groundwater quality evaluation using Shannon information theory and human health risk assessment in Yazd province, central plateau of Iran. Environ Sci Pollut Res 28:1108-1130 https://doi.org/10.1007/s11356-020-10362-6

Amiri V, Li P, Bhattacharya P, Nakhaei M (2021c) Mercury pollution in the coastal Urmia aquifer in northwestern Iran: potential sources, mobility, and toxicity. Environ Sci Pollut Res https://doi.org/10.1007/s11356-020-11865-y

Amiri V, Nakhaei M, Lak R, Kholghi M (2016a) Assessment of seasonal groundwater quality and potential saltwater intrusion: a study case in Urmia coastal aquifer (NW Iran) using the groundwater quality index (GQI) and hydrochemical facies evolution diagram (HFE-D). Stoch Environ Res Risk Assess 30:1473-1484. https://doi.org/10.1007/s00477-015-1108-3

Amiri V, Nakhaei M, Lak R, Kholghi M (2016b) Geophysical, isotopic, and hydrogeochemical tools to identify potential impacts on coastal groundwater resources from Urmia hypersaline Lake, NW Iran. Environ Sci Pollut Res 23:16738-16760. https://doi.org/10.1007/s11356$\underline{016-6859-y}$ 
Amiri V, Nakhaei M, Lak R, Kholghi M (2016c) Investigating the salinization and freshening processes of groundwater through major ion and trace element indicators: Urmia plain, NW of Iran. Environ Monit Assess 188:233. https://doi.org/10.1007/s10661-016-5231-5

Amiri V, Nakhaei, M, Lak R (2017) Using radon-222 and radium-226 isotopes to deduce the functioning of a coastal aquifer adjacent to a hypersaline lake in NW Iran. J Asian Earth Sci 147:128-147. https://doi.org/10.1016/j.jseaes.2017.07.015

Bech, J., Tume P., Longan L., Reverter F (2005) Baseline concentrations of trace elements in surface soils of the Torreles and Saint Climent municipal districts (Catalonia, Spain). Environ Monit Assess 108(1-3): 309-322. https://doi.org/10.1007/s10661-005-4331-4

Biddau R, Cidu R, Lorrai M, Mulas MG (2017) Assessing background values of chloride, sulfate and fluoride in groundwater: A geochemical-statistical approach at a regional scale. J Geochem Explor 181: 243-255. https://doi.org/10.1016/j.gexplo.2017.08.002

Bulut OF, Duru B, Çakmak O, Günhan O, Dilek FB, Yetis U (2020) Determination of groundwater threshold values: A methodological approach. J Clean Prod 253:120001. https://doi.org/10.1016/j.jclepro.2020.120001

Cruz JV, Andrade C (2015) Natural background groundwater composition in the Azores archipelago (Portugal): a hydrogeochemical study and threshold value determination. Sci Total Environ 520:127-35. https://doi.org/10.1016/j.scitotenv.2015.03.057

De Caro M, Crosta GB, Frattini P (2017) Hydrogeochemical characterization and Natural Background Levels in urbanized areas: Milan Metropolitan area (Northern Italy). J Hydrol 547: 455-473. https://doi.org/10.1016/j.jhydrol.2017.02.025

Duan M, Du X, Peng W, Jiang C, Zhang S, Ding Y, Yan L (2020) Importance of surface water background values for objectively assessing water quality in a unique basin. Sci Total Environ 722: 137922. https://doi.org/10.1016/j.scitotenv.2020.137922

Duan M, Du X, Peng W, Zhang S, Yan L (2019) A Revised Method of Surface Water Quality Evaluation Based on Background Values and Its Application to Samples Collected in Heilongjiang Province, China. Water 11:1057. https://doi.org/10.3390/w11051057

Ducci D, Condesso de Melo MT, Preziosi E, Sellerino M, Parrone D, Ribeiro L (2016) Combining natural background levels (NBLs) assessment with indicator kriging analysis to improve groundwater quality data interpretation and management. Sci Total Environ 569570:569-584. https://doi.org/10.1016/j.scitotenv.2016.06.184. 
628 Edmunds WM, Shand P, Hart P, Ward RS (2003) The natural (baseline) quality of groundwater: a UK pilot study. Sci Total Environ 310(1-3):25-35. https://doi.org/10.1016/s00489697(02)00620-4

European Community (2006) Groundwater directive 2006/118/CE. Directive of the European Parliament and of the Council on the Protection of Groundwater Against Pollution and Deterioration, OJ L372, 27/12/2006, pp. 19-31.

Falkenmark M (2005) Water Usability Degradation. Water International 30(2):136-146. https://doi.org/10.1080/02508060508691854

Gałuszka A (2006) A review of geochemical background concepts and an example using data from Poland. Environ Geol 52(5): 861-870. https://doi.org/10.1007/s00254-006-0528-2

Gao Y, Qian H, Huo C, Chen J, Wang H (2020) Assessing natural background levels in shallow groundwater in a large semiarid Drainage Basin. J Hydrol https://doi.org/10.1016/j.jhydrol.2020.124638

Gao Y, Qian H, Wang H, Chen J, Ren W, Yang F (2019) Assessment of background levels and pollution sources for arsenic and fluoride in the phreatic and confined groundwater of Xi'an city, Shaanxi, China. Environ Sci Pollut Res 27:34702-34714. https://doi.org/10.1007/s11356-019-06791-7

Hawkes HE, Webb JS (1962) Geochemistry in Mineral Exploration. New York: Harper.

Hernandez-Garcia ME, Custodio E (2004) Natural baseline quality of Madrid Tertiary Detrital Aquifer groundwater (Spain): A basis for aquifer management. Environ Geol 46(2):173-188. https://doi.org/10.1007/s00254-004-1024-1

IWRM (Iran Water Resources Management) (2017), Groundwater Resuscitation and Balancing plan of the Country.

Ji Y, Wu J, Wang Y, Elumalai V, Subramani T (2020) Seasonal variation of drinking water quality and human health risk assessment in Hancheng City of Guanzhong Plain, China.

657 Kim K-H, Yun S-T, Kim H-K, Kim J-W (2015) Determination of natural backgrounds and 658 thresholds of nitrate in South Korean groundwater using model-based statistical approaches. 
$660 \quad$ https://doi.org/10.1016/j.gexplo.2014.10.001

661 Li X, Li J, Sui H, He L, Cao X, Li Y (2018) Evaluation and determination of soil remediation schemes using a modified AHP model and its application in a contaminated coking plant. J Hazard Mater 353: 300-311. https://doi.org/10.1016/j.jhazmat.2018.04.010

Li P, Qian H, Howard KWF, Wu J, Lyu X (2014) Anthropogenic pollution and variability of manganese in alluvial sediments of the Yellow River, Ningxia, northwest China. Environ Monit Assess 186(3):1385-1398. https://doi.org/10.1007/s10661-013-3461-3

Li P, Wu J, Qian H, Zhang Y, Yang N, Jing L, Yu P (2016) Hydrogeochemical characterization of groundwater in and around a wastewater irrigated forest in the southeastern edge of the Tengger Desert, Northwest China. Expo Health 8(3):331-348. https://doi.org/10.1007/s12403-016-0193-y

Li P, Tian R, Xue C, Wu J (2017) Progress, opportunities and key fields for groundwater quality research under the impacts of human activities in China with a special focus on western China. Environ Sci Pollut Res 24(15):13224-13234. https://doi.org/10.1007/s11356-0178753-7

Li P, He X, Guo W (2019) Spatial groundwater quality and potential health risks due to nitrate ingestion through drinking water: a case study in Yan'an City on the Loess Plateau of northwest China. Hum Ecol Risk Assess 25(1-2):11-31. https://doi.org/10.1080/10807039.2018.1553612

Li P, Karunanidhi D, Subramani T, Srinivasamoorthy K (2021) Sources and consequences of groundwater contamination. Arch Environ Contam Toxicol 80(1):1-10. https://doi.org/10.1007/s00244-020-00805-Z

Sun L (2019) Calculating Environmental Background Value: A Comparative Study of Statistical Versus Spatial Analyses. Pol J Environ Stud 28(1):197-203 https://doi.org/10.15244/pjoes/84837

Masetti M, Poli S, Sterlacchini S, Beretta GP, Facchi A (2008) Spatial and statistical assessment of factors influencing nitrate contamination in groundwater. J Environ Manag 86:272-281. https://doi.org/10.1016/j.jenvman.2006.12.023

Matschullat J, Ottenstein R, Reimann C (2000) Geochemical background Can we calculate it? Environ Geol 39(9): 990-1000. https://doi.org/10.1007/s002549900084 
Mencio A, Mas-Pla J, Otero N, Regas O, Boy-Roura M, Puig R, Bach J, Domenech C, Zamorano M, Brusi D, Folch A (2016) Nitrate pollution of groundwater; all right..., but nothing else? Sci Total Environ 539:241-251. https://doi.org/10.1016/j.scitotenv.2015.08.151

Molinari A, Guadagnini L, Marcaccio M, Guadagnini A (2012) Natural background levels and threshold values of chemical species in three large-scale groundwater bodies in northern Italy. Sci Total Environ 425:9-19. https://doi.org/10.1016/j.scitotenv.2012.03.015

Muller D, Blum A, Hart A, Hookey J, Kunkel R, Scheidleder A, Tomlin C, Wendland F (2006) Final proposal for a methodology to set up groundwater threshold values in Europe. Report to the EU project "BRIDGE" 2006, Deliverable D18.

Nakhaei M, Amiri V, Rezaei K, Moosaei F (2015) An investigation of the potential environmental contamination from the leachate of the Rasht waste disposal site in Iran. Bull Eng Geol Environ 74(1):233-246. https://doi.org/10.1007/s10064-014-0577-9

Nakic Z, Posavec K, Bacani A (2007) A visual basic spreadsheet macro for geochemical background analysis. Ground Water 45(5):642-7. https://doi.org/10.1111/j.17456584.2007.00325.x

Parrone D, Ghergo S, Preziosi E (2019) A multi-method approach for the assessment of natural background levels in groundwater. Sci Total Environ 659:884-894. https://doi.org/10.1016/j.scitotenv.2018.12.350

Preziosi E, Giuliano G, Vivona R (2010) Natural background levels and threshold values derivation for naturally As, $\mathrm{V}$ and $\mathrm{F}$ rich groundwater bodies: a methodological case study in Central Italy. Environ Earth Sci 61:885-897. https://doi.org/10.1007/s12665-009-0404-y

Preziosi, E., Parrone, D., Del Bon, A., Ghergo, S., 2014. Natural background level assessment in groundwaters: probability plot versus pre-selection method. J Geochem Explor 143:43-53. https://doi.org/10.1016/j.gexplo.2014.03.015

Rahman A, Mondal NC, Fauzia F (2020) Arsenic enrichment and its natural background in groundwater in the proximity of active floodplains of Ganga River, Northern India. Chemosphere https://doi.org/10.1016/j.chemosphere.2020.129096

Ren X, Li P, He X, Su F, Elumalai V (2021) Hydrogeochemical processes affecting groundwater chemistry in the central part of the Guanzhong Basin, China. Arch Environ Contam Toxicol 80(1):74-91. https://doi.org/10.1007/s00244-020-00772-5 
Reimann C, Garrett RG (2005) Geochemical background-concept and reality. Sci Total Environ 350(1-3):12-27. https://doi.org/10.1016/j.scitotenv.2005.01.047

Rodrigues ASL, Malafaia G, Costa AT, Júnior HAN (2013) Background values for chemical elements in sediments of the Gualaxo Do Norte River Basin, Mg, Brazil. Revista De Ciências Ambientais, Canoas, 7, 2

Rotiroti M, Di Mauro B, Fumagalli L, Bonomi T (2015) COMPSEC, a new tool to derive natural background levels by the component separation approach: application in two different hydrogeological contexts in northern Italy. J Geochem Explor 158:44-54. https://doi.org/10.1016/j.gexplo.2015.06.017

Salomão GN, Dall'Agnol R, Sahoo PK, Júnior JSF, Silva MS, Filho PWMS, Berrêdo JF, Nascimento Junior WR, Costa MF (2018) Geochemical distribution and threshold values determination of heavy metals in stream water in the sub-basins of Vermelho and Sororó rivers, Itacaiúnas River watershed, Eastern Amazon, Brazil. Geochimica Brasiliensis 32(2):180-198. https://doi.org/10.21715/GB2358-2812.2018322180

Salomão GN, Figueiredo MA, Dall'Agnol R, Sahoo PK, Filho CAM, Costa MF, Angélica RS (2019) Geochemical mapping and background concentrations of iron and potentially toxic elements in active stream sediments from Carajás, Brazil -implication for risk assessment. J S Am Earth Sci 92:151-166 https://doi.org/10.1016/j.jsames.2019.03.014

Sellerino M, Forte G, Ducci D (2019) Identification of the natural background levels in the Phlaegrean fields groundwater body (Southern Italy). J Geochem Explor 200:181-192. https://doi.org/10.1016/j.gexplo.2019.02.007

Shapiro SS, Wilk MB (1965) An analysis of variance test for normality (complete samples). Biometrika 52:591. https://doi.org/10.2307/2333709

Sohrabi N, Chitsazan M, Amiri V, Moradi Nezhad T (2013) Evaluation of groundwater resources in alluvial aquifer based on MODFLOW program, case study: Evan plain (Iran). Int J Agri Crop Sci 5(11):1164-1170.

Sohrabi N, Kalantari N, Amiri V (2018) An evaluation of the distribution and behavior of uranium in Urmia aquifer. Iran- Water Resour Res 14(3):236-252 (In Persian)

Sohrabi N, Kalantari N, Amiri V, Nakhaei M (2017) Assessing the chemical behavior and spatial distribution of yttrium and rare earth elements (YREEs) in a coastal aquifer adjacent to the 
Urmia Hypersaline Lake, NW Iran. Environ Sci Pollut Res 24(25):20502-20520. https://doi.org/10.1007/s11356-017-9644-7

753 Sohrabi N, Kalantari N, Amiri V, Saha N, Berndtsson R, Bhattacharya P, Ahmad A (2020) A

754 Probabilistic-Deterministic Analysis of Human Health Risk Related to the Exposure to Potentially Toxic Elements in Groundwater of Urmia Coastal Aquifer (NW of Iran) with a Special Focus on Arsenic Speciation and Temporal Variation. Stoch Environ Res Risk Assess https://doi.org/10.1007/s00477-020-01934-6

Su Z, Wu J, He X, Elumalai V (2020) Temporal changes of groundwater quality within the groundwater depression cone and prediction of confined groundwater salinity using Grey Markov model in Yinchuan area of northwest China. Expo Health 12(3):447-468. https://doi.org/10.1007/s12403-020-00355-8

Succop PA, Clark S, Chen M, Galke W (2004) Imputation of data values that are less than a

Urresti-Estala B, Carrasco-Cantos F, Vadillo-Perez I, Jimenez-Gavilan P (2013) Determination

Vázquez-Suñé E, Sánchez-Vila X, Carrera J (2004) Introductory review of specific factors influencing urban groundwater, an emerging branch of hydrogeology, with reference to Barcelona, Spain. Hydrogeol J 13(3): 522-533. https://doi.org/10.1007/s10040-004-0360-2

Wang W, Zhang Z, Duan L, et al. (2018) Response of the groundwater system in the Guanzhong

Wang D, Wu J, Wang Y, Ji Y (2020) Finding High-Quality Groundwater Resources to Reduce Basin (central China) to climate change and human activities. Hydrogeol J 26(5):1429-1441.

Wendland F, Hannappel S, Kunkel R, Schenk R, Voigt HJ, Wolter R (2005) A procedure to define natural groundwater conditions of groundwater bodies in Germany. Water Sci Technol 51(3-4): 249-257. https://doi.org/10.2166/wst.2005.0598 
782 Wu J, Wang L, Wang S, Tian R, Xue C, Feng W, Li Y (2017) Spatiotemporal variation of 783 groundwater quality in an arid area experiencing long-term paper wastewater irrigation, 784 northwest China. Environ Earth Sci 76(13):460. https://doi.org/10.1007/s12665-017-6787-2

785 Yan Y, Han L, Yu R-L, Hu G-R, Zhang W-F, Cui J-Y, Yan Y, Huang H-B (2020) Background 786 determination, pollution assessment and source analysis of heavy metals in estuarine 787 sediments from Quanzhou Bay, southeast China. Catena 187: 104322. $788 \quad$ https://doi.org/10.1016/j.catena.2019.104322 

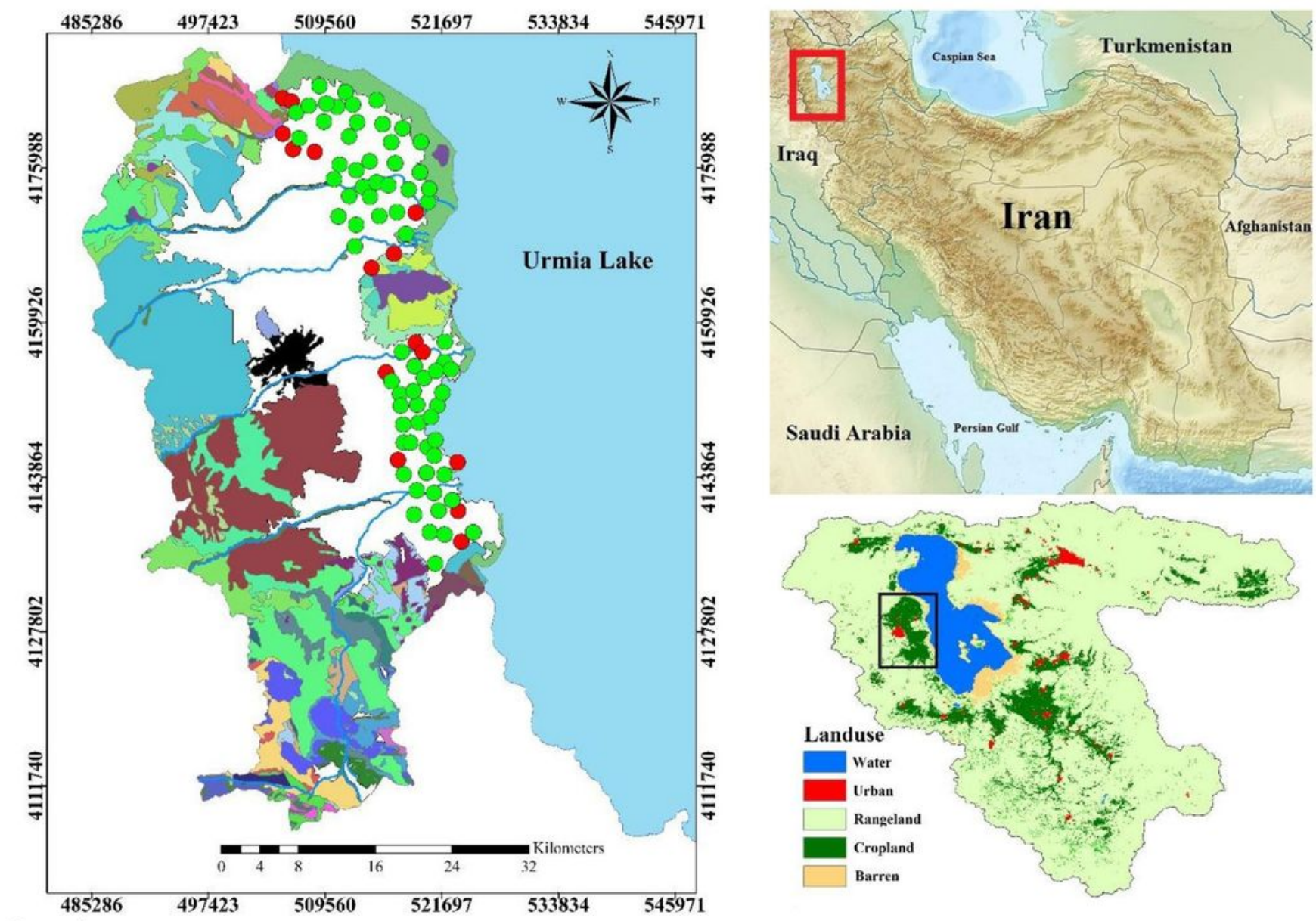

Legend

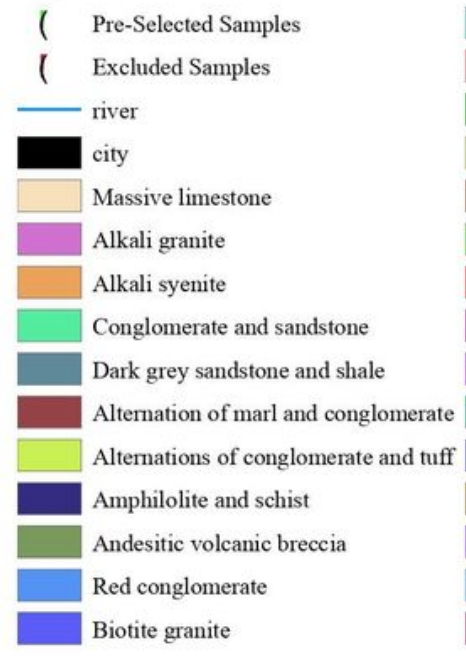

\begin{tabular}{|l|l}
\hline & Conglomeratic sandstone \\
\hline & Coarse grey sandstone and siltstone \\
Dioritic gabbro \\
\hline \\
Coloured shale \\
Conglomerate with faint cement \\
Thick fossilliferous limestones \\
Dolomite and dolomitic limestone \\
Creamy limestone \\
Dacitic dome \\
Basaltic lava and spilitic basalt \\
Pyroxenite \\
Ghoshchi granite \\
Gravel fan \\
Green shale,siltstone and sandstone \\
Grey to greenish marly limestone
\end{tabular}

Layered gabbro, anorthosite, norite Limestone (Paleocene-Early Eocene) Limestone and dolomitic limestone Limestone, dolomite and shale Salty flat Marble Gniess, amphibolite andmeta-diorite Metamorphosed tuff and rhyolite Microdiorites and pyroxene porphyries Sandstone and conglomerate Basic \& acidic volcanic rocks Old terraces

Ophiolite melange

Paleozoic undifferentiated

Crystalized limestone

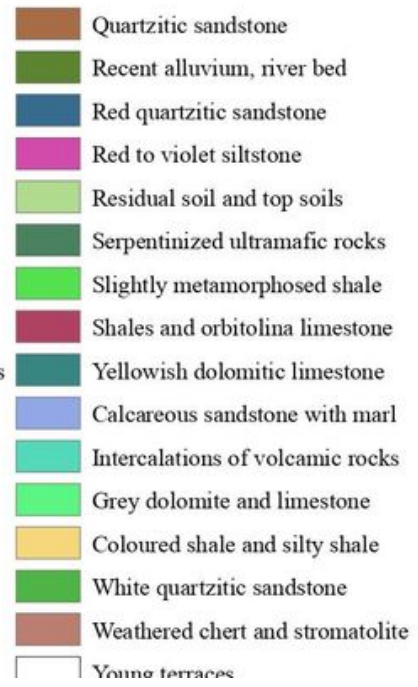

\section{Figure 1}

Geographical location of the study area. Green circles: included water samples, red circles: excluded water samples Note: The designations employed and the presentation of the material on this map do not imply the expression of any opinion whatsoever on the part of Research Square concerning the legal 
status of any country, territory, city or area or of its authorities, or concerning the delimitation of its frontiers or boundaries. This map has been provided by the authors.

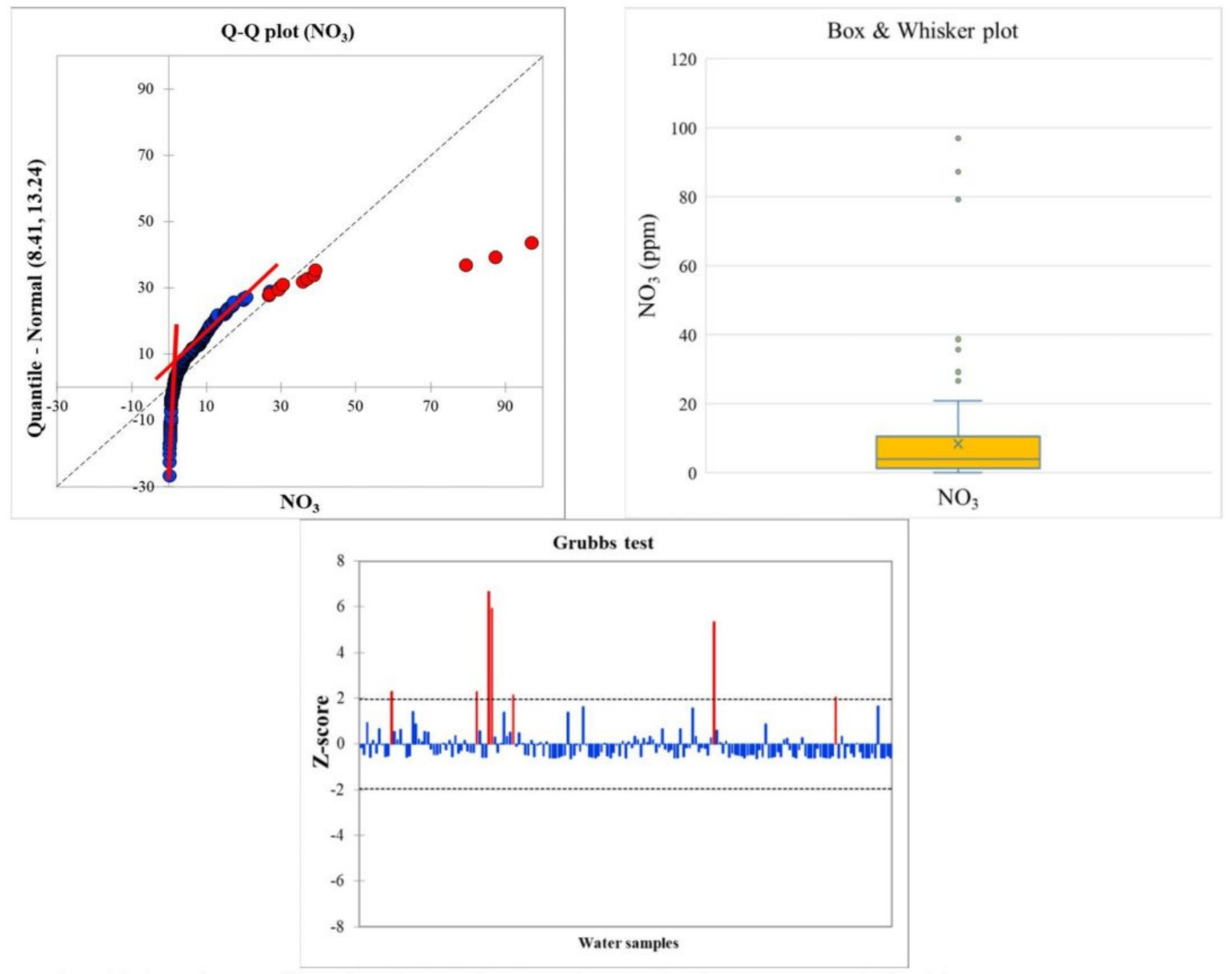

Figure 2

Identifying the outliers in nitrate data set by Q-Q plot, BW, and Grubbs test. 

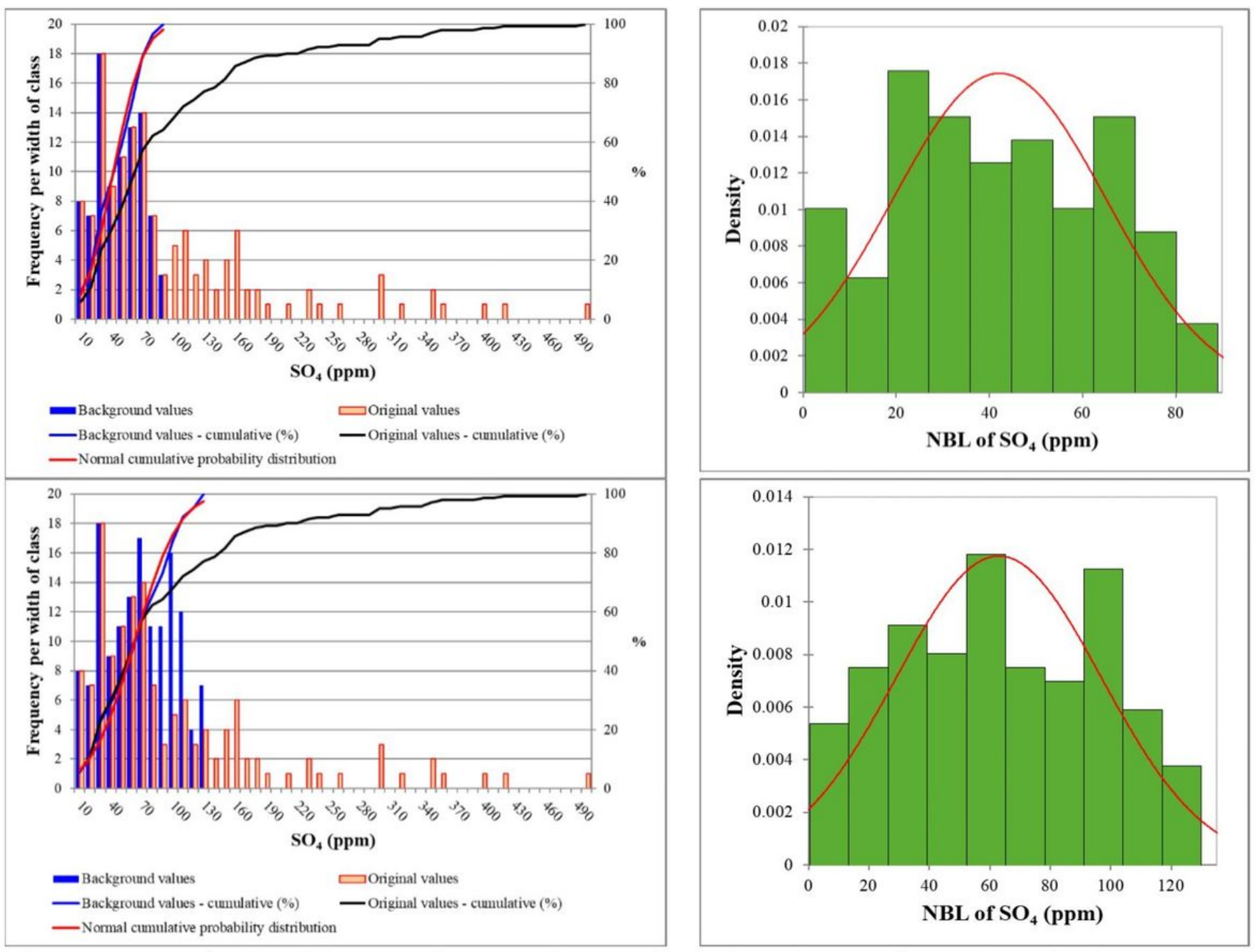

Figure 3

NBL calculated for SO4 by Iterative $2 \sigma$ (upper) and CDF (lower) methods. 

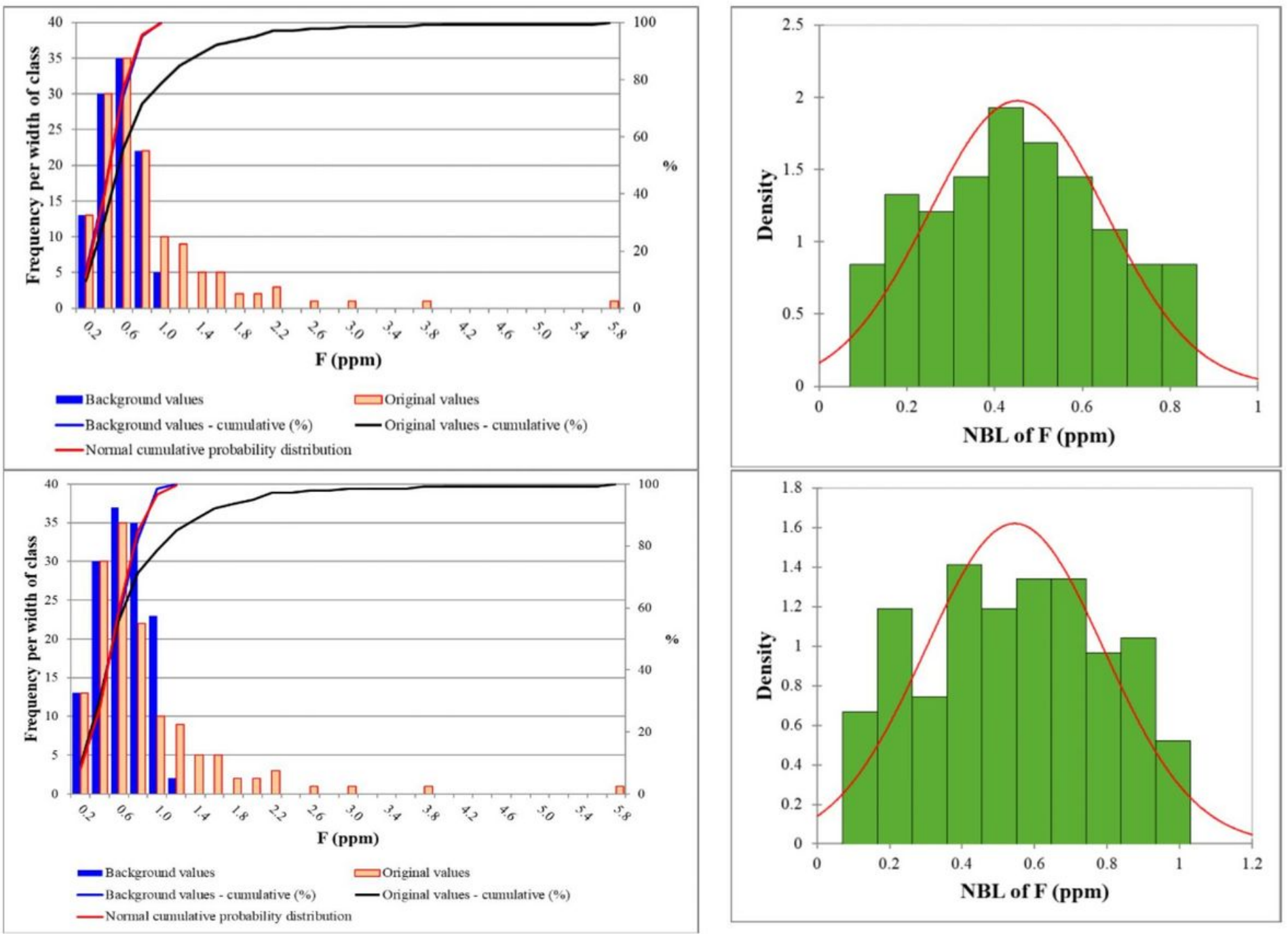

Figure 4

NBL calculated for F by Iterative $2 \sigma$ (upper) and CDF (lower) methods. 

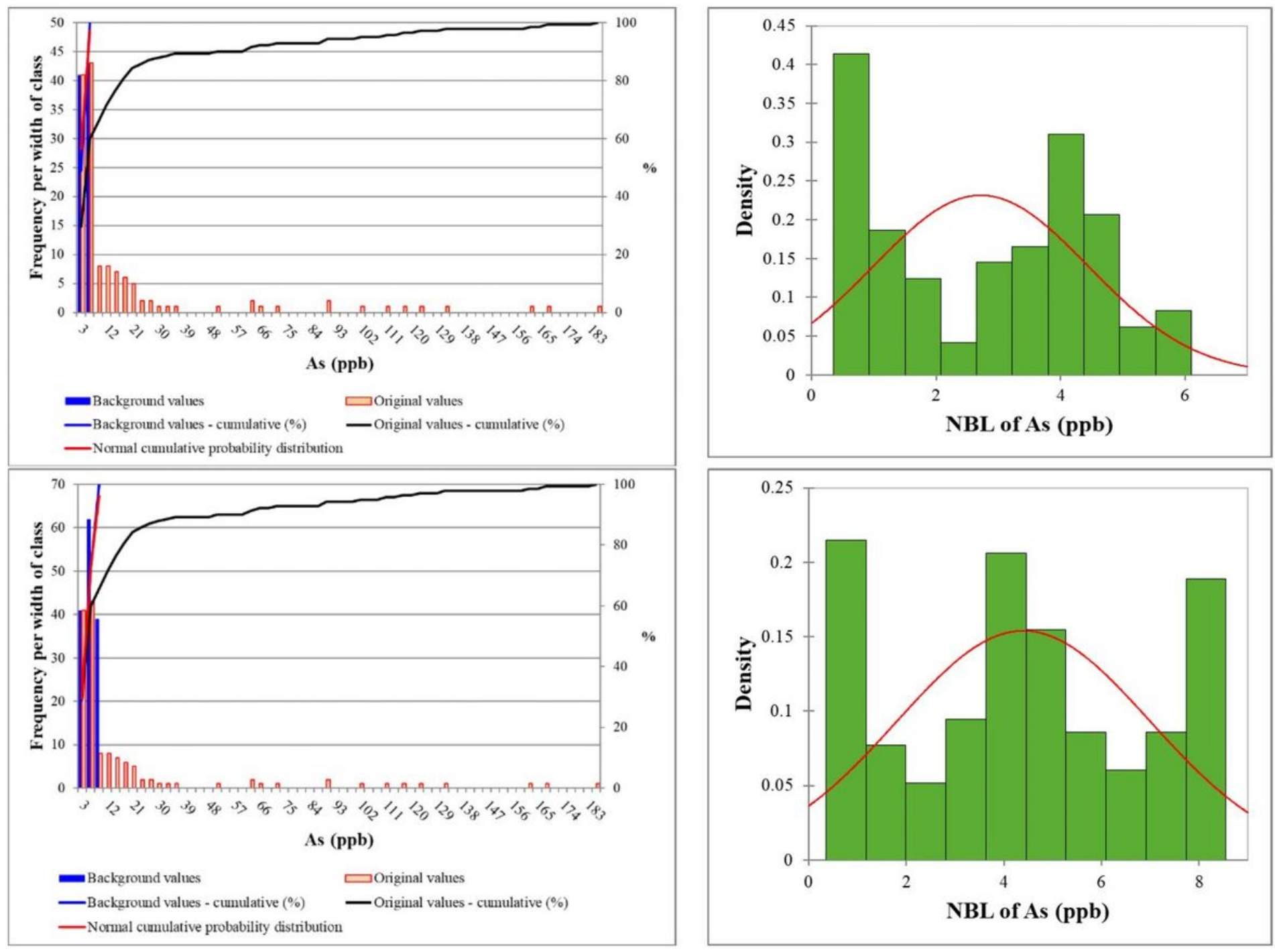

Figure 5

NBL calculated for As by Iterative $2 \sigma$ (upper) and CDF (lower) methods. 

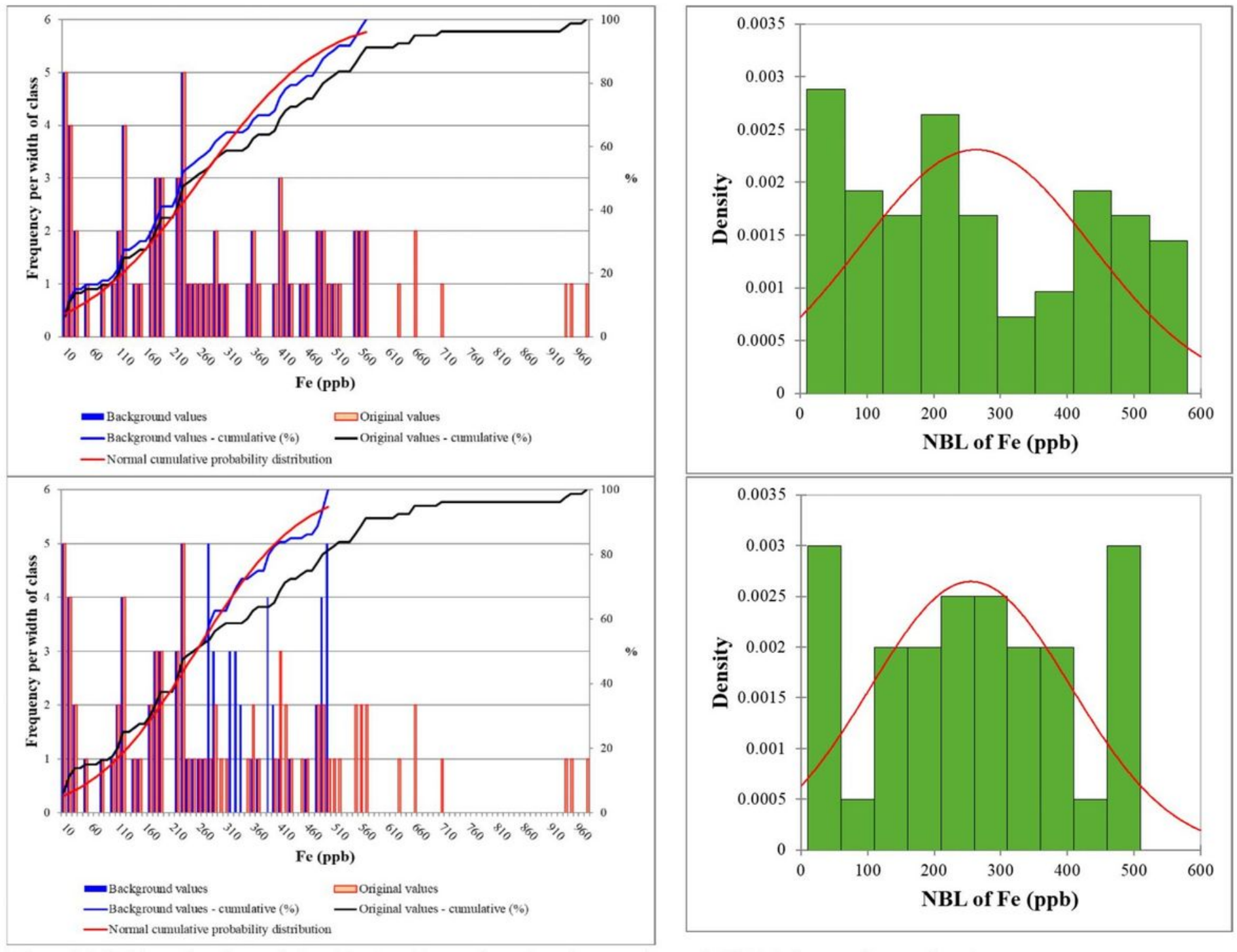

Figure 6

NBL calculated for Fe by Iterative $2 \sigma$ (upper) and CDF (lower) methods. 

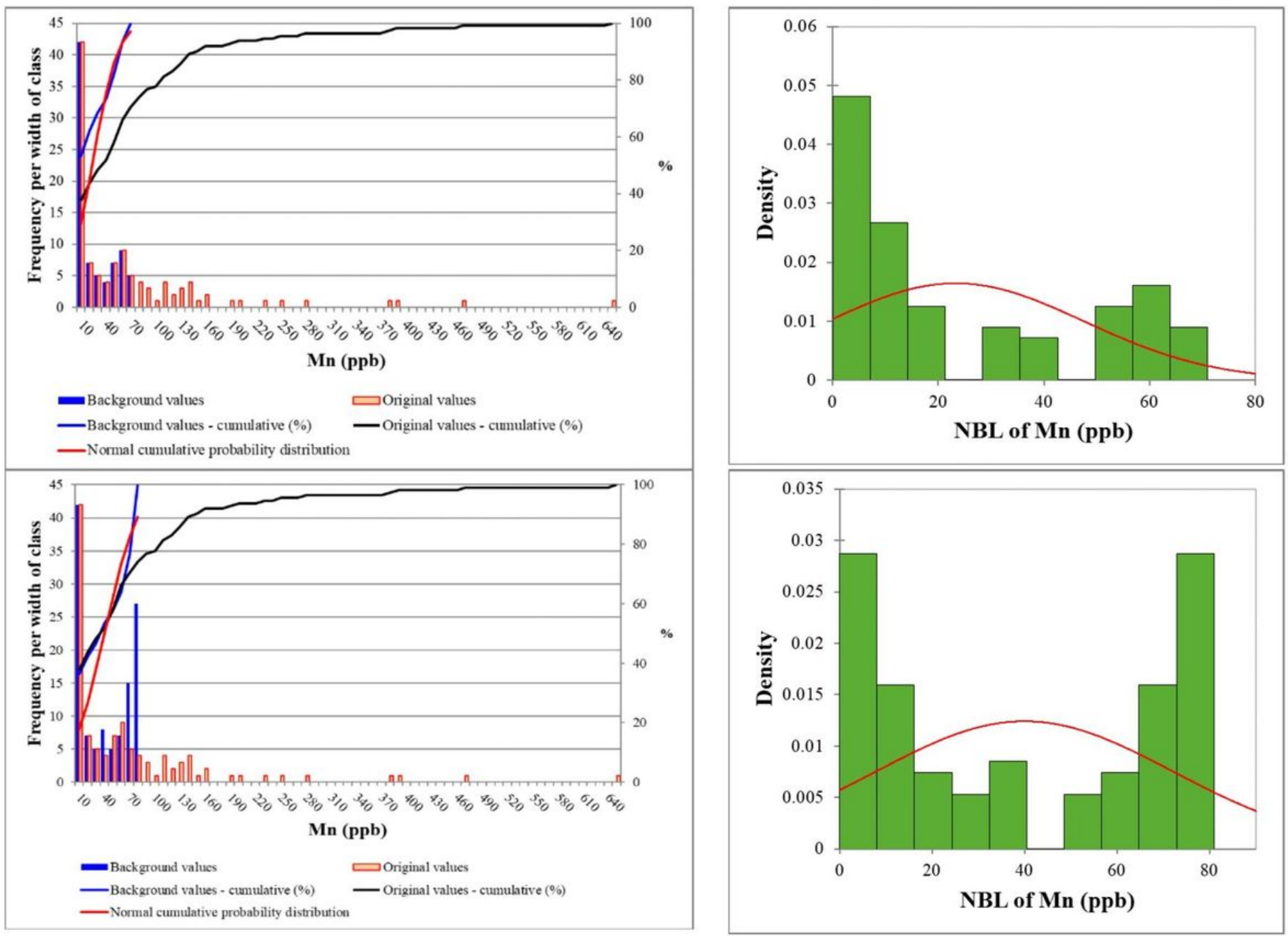

Figure 7

NBL calculated for Mn by Iterative $2 \sigma$ (upper) and CDF (lower) methods.

\section{Supplementary Files}

This is a list of supplementary files associated with this preprint. Click to download.

- SupplementaryFigures.docx 